\title{
THE
}

\section{Role of convection in redistributing formaldehyde to the upper troposphere over North America and the North Atlantic during the summer 2004 INTEX campaign}

\author{
Alan Fried \\ Haiwei Shen \\ University of Rhode Island \\ et al
}

Follow this and additional works at: https://digitalcommons.uri.edu/gsofacpubs

Terms of Use

All rights reserved under copyright.

\section{Citation/Publisher Attribution}

Fried, A., et al. (2008), Role of convection in redistributing formaldehyde to the upper troposphere over North America and the North Atlantic during the summer 2004 INTEX campaign, J. Geophys. Res., 113, D17306, doi: 10.1029/2007JD009760.

Available at: https://doi.org/10.1029/2007JD009760

This Article is brought to you for free and open access by the Graduate School of Oceanography at DigitalCommons@URI. It has been accepted for inclusion in Graduate School of Oceanography Faculty Publications by an authorized administrator of DigitalCommons@URI. For more information, please contact digitalcommons-group@uri.edu. 


\section{Role of convection in redistributing formaldehyde to the upper troposphere over North America and the North Atlantic during the summer 2004 INTEX campaign}

Alan Fried, ${ }^{1}$ Jennifer R. Olson, ${ }^{2}$ James G. Walega, ${ }^{1}$ Jim H. Crawford, ${ }^{2}$ Gao Chen, ${ }^{2}$ Petter Weibring, ${ }^{1}$ Dirk Richter, ${ }^{1}$ Chad Roller, ${ }^{1,3}$ Frank Tittel, ${ }^{4}$ Michael Porter, ${ }^{5}$ Henry Fuelberg, ${ }^{5}$ Jeremy Halland, ${ }^{5}$ Timothy H. Bertram, ${ }^{6}$ Ronald C. Cohen, ${ }^{6}$ Kenneth Pickering, ${ }^{7}$ Brian G. Heikes, ${ }^{8}$ Julie A. Snow, ${ }^{9}$ Haiwei Shen, ${ }^{8}$ Daniel W. O’Sullivan, ${ }^{10}$ William H. Brune, ${ }^{11}$ Xinrong Ren, ${ }^{11}$ Donald R. Blake, ${ }^{12}$ Nicola Blake, ${ }^{12}$ Glen Sachse, ${ }^{2}$ Glenn S. Diskin, ${ }^{2}$ James Podolske, ${ }^{13}$ Stephanie A. Vay, ${ }^{2}$ Richard E. Shetter, ${ }^{14}$ Samuel R. Hall, ${ }^{14}$ Bruce E. Anderson, ${ }^{2}$ Lee Thornhill, ${ }^{2}$ Antony D. Clarke, ${ }^{15}$ Cameron S. McNaughton, ${ }^{15}$ Hanwant B. Singh, ${ }^{13}$ Melody A. Avery, ${ }^{2}$ Gregory Huey, ${ }^{16}$ Saewung Kim, ${ }^{16}$ and Dylan B. Millet, ${ }^{17,18}$

Received 24 December 2007; revised 26 March 2008; accepted 19 June 2008; published 5 September 2008.

[1] Measurements of formaldehyde $\left(\mathrm{CH}_{2} \mathrm{O}\right)$ from a tunable diode laser absorption spectrometer (TDLAS) were acquired onboard the NASA DC-8 aircraft during the summer 2004 INTEX-NA campaign to test our understanding of convection and $\mathrm{CH}_{2} \mathrm{O}$ production mechanisms in the upper troposphere (UT, 6-12 km) over continental North America and the North Atlantic Ocean. The present study utilizes these TDLAS measurements and results from a box model to (1) establish sets of conditions by which to distinguish "background" UT $\mathrm{CH}_{2} \mathrm{O}$ levels from those perturbed by convection and other causes; (2) quantify the $\mathrm{CH}_{2} \mathrm{O}$ precursor budgets for both air mass types; (3) quantify the fraction of time that the UT $\mathrm{CH}_{2} \mathrm{O}$ measurements over North America and North Atlantic are perturbed during the summer of 2004; (4) provide estimates for the fraction of time that such perturbed $\mathrm{CH}_{2} \mathrm{O}$ levels are caused by direct convection of boundary layer $\mathrm{CH}_{2} \mathrm{O}$ and/or convection of $\mathrm{CH}_{2} \mathrm{O}$ precursors; (5) assess the ability of box models to reproduce the $\mathrm{CH}_{2} \mathrm{O}$ measurements; and (6) examine $\mathrm{CH}_{2} \mathrm{O}$ and $\mathrm{HO}_{2}$ relationships in the presence of enhanced NO. Multiple tracers were used to arrive at a set of UT $\mathrm{CH}_{2} \mathrm{O}$ background and perturbed air mass periods, and $46 \%$ of the TDLAS measurements fell within the latter category. In general, production of $\mathrm{CH}_{2} \mathrm{O}$ from $\mathrm{CH}_{4}$ was found to be the dominant source term, even in perturbed air masses. This was followed by production from methyl hydroperoxide, methanol, PAN-type compounds, and ketones, in descending order of their contribution. At least $70 \%$ to $73 \%$ of the elevated UT observations were caused by enhanced production from $\mathrm{CH}_{2} \mathrm{O}$ precursors rather than direct transport of $\mathrm{CH}_{2} \mathrm{O}$ from the boundary layer. In the presence of elevated $\mathrm{NO}$, there was a definite trend in the $\mathrm{CH}_{2} \mathrm{O}$ measurement-model discrepancy, and this was highly correlated with $\mathrm{HO}_{2}$ measurement-model discrepancies in the UT.

Citation: Fried, A., et al. (2008), Role of convection in redistributing formaldehyde to the upper troposphere over North America and the North Atlantic during the summer 2004 INTEX campaign, J. Geophys. Res., 113, D17306, doi:10.1029/2007JD009760.

\footnotetext{
${ }^{1}$ Earth Observing Laboratory, National Center for Atmospheric Research, Boulder, Colorado, USA.

${ }^{2}$ NASA Langley Research Center, Hampton, Virginia, USA.

${ }^{3}$ Ekips Technologies, Norman, Oklahoma, USA.

${ }^{4}$ Rice University, Houston, Texas, USA.

${ }^{5}$ Florida State University, Tallahassee, Florida, USA.

${ }^{6}$ University of California, Berkeley, Berkeley, California, USA.

${ }^{7}$ NASA Goddard Space Flight Center, Greenbelt, Maryland, USA.

${ }^{8}$ University of Rhode Island, Narragansett, Rhode Island, USA.
}

\footnotetext{
${ }^{9}$ Slippery Rock University, Slippery Rock, Pennsylvania, USA.

${ }^{10}$ United States Naval Academy, Annapolis, Maryland, USA. USA.

${ }^{11}$ Pennsylvania State University, University Park, Pennsylvania,

${ }^{12}$ University of California, Irvine, California, USA.

${ }^{13}$ NASA Ames Research Center, Moffett Field, California, USA.

${ }^{14}$ Atmospheric Chemistry Division, NCAR, Boulder, Colorado, USA.

${ }^{15}$ University of Hawaii, Manoa, Hawaii, USA.

${ }^{16}$ Georgia Institute of Technology, Atlantic, Georgia, USA.

${ }^{17}$ Harvard University, Cambridge, Massachusetts, USA.

${ }^{18}$ Now at University of Minnesota, Minnesota, USA.
} 


\section{Introduction}

[2] The companion paper by Fried et al. [2008] discusses the role and importance of formaldehyde $\left(\mathrm{CH}_{2} \mathrm{O}\right)$ throughout the troposphere. That paper also provides an overview of $\mathrm{CH}_{2} \mathrm{O}$ measurements and modeling approaches employed, the modeling constraints, and measurement-model comparisons during the Intercontinental Transport ExperimentNorth America (INTEX-NA). As described in the overview paper by Singh et al. [2006], the INTEX-NA study was carried out during the summer of 2004 (1 July to 15 August 2004) over North America and the Atlantic Ocean on the NASA DC-8 airplane. The present study utilizes the results presented by Fried et al. [2008] to further examine the role of convection in transporting $\mathrm{CH}_{2} \mathrm{O}$ and its precursors to the upper troposphere (UT, defined here as pressure altitudes extending from 6 to $12 \mathrm{~km}$ ) during the summer of 2004 .

[3] There is a growing body of evidence that photolysis of additional $\mathrm{HO}_{x}\left(\mathrm{OH}+\mathrm{HO}_{2}\right)$ precursors, such as $\mathrm{CH}_{2} \mathrm{O}$, $\mathrm{H}_{2} \mathrm{O}_{2}$, and $\mathrm{CH}_{3} \mathrm{OOH}$ (methyl hydroperoxide, MHP) are more important in producing $\mathrm{HO}_{x}$ radicals and ultimately $\mathrm{O}_{3}$ in the upper troposphere than previously thought. These precursors are thought to be transported from lower altitudes [Wennberg et al., 1998; Jaeglé et al., 1997; Prather and Jacob, 1997; Brune et al., 1998; Jaeglé et al., 1998a, 1998b, 2000; Faloona et al., 2000; Müller and Brasseur, 1999; Cohan et al., 1999; Ravetta et al., 2001; Wang and Prinn, 2000; Crawford et al., 1999]. These studies revealed the importance of deep tropical convection, as well as deep convection from the continental boundary layer on upper tropospheric $\mathrm{HO}_{x}$ levels. As $\mathrm{O}_{3}$ production in the UT is almost directly proportional to the $\mathrm{HO}_{x}$ mixing ratio [Jaeglé et al., 1998a; Müller and Brasseur, 1999], a comprehensive knowledge of upper tropospheric $\mathrm{HO}_{x}$ sources is thus essential for understanding $\mathrm{UT} \mathrm{O}_{3}$.

[4] Although UT measurements of $\mathrm{CH}_{2} \mathrm{O}, \mathrm{H}_{2} \mathrm{O}_{2}$, and MHP have recently been acquired and examined over the Mediterranean basin during the MINOS study [Kormann et al., 2003; Lelieveld et al., 2002] and over central Europe and the Mediterranean basin during the UTOPIHAN study in the summer [Colomb et al., 2006; Stickler et al., 2006], there is a paucity of similar measurements and analyses over North America during summer months. These four papers clearly showed that continental convection of polluted boundary layer sources can significantly affect upper tropospheric $\mathrm{HO}_{x}$ levels. While airborne measurements have been acquired for these same three gases over North America and over the North Atlantic Ocean on various platforms [Kleinman et al., 2005; Dasgupta et al., 2005; Fried et al., 2002; Lee et al., 1998; Nunnermacker et al., 2004; Wert et al., 2003, and references therein], these studies have not focused on UT chemistry and the role of convection; all the measurements were acquired below $7 \mathrm{~km}$ and more typically at much lower altitudes below $\sim 4 \mathrm{~km}$ over urban areas. In fact, with the exception of the Jaeglé et al. [2000] study during the SONEX campaign, to our knowledge, there are no comparable UT data to the European studies prior to the INTEX-NA campaign for $\mathrm{CH}_{2} \mathrm{O}$, $\mathrm{H}_{2} \mathrm{O}_{2}$, and $\mathrm{CH}_{3} \mathrm{OOH}$ focusing on North America and the role of convective transport. Moreover, as the SONEX study primarily focused on the North Atlantic during the fall, there is only partial coverage over the continental United States and no coverage during the summer months when photochemical activity is high and deep convection from severe thunderstorm activity can be significant.

[5] This study is the last in a series of four papers, based upon observations and model results during the INTEX-NA study examining UT convection of $\mathrm{CH}_{2} \mathrm{O}$. The first paper by Millet et al. [2006], discussed $\mathrm{CH}_{2} \mathrm{O}$ distributions over North America and implications for satellite retrievals. The second paper by Snow et al. [2007] showed the importance of convection in transporting the aforementioned gases to the UT and compared and contrasted these results with two other airborne campaigns. The third paper by Fried et al. [2008] discussed two airborne $\mathrm{CH}_{2} \mathrm{O}$ instruments onboard the NASA DC-8 aircraft during INTEX-NA: a tunable diode laser absorption spectrometer (TDLAS) from the National Center for Atmospheric Research (NCAR), and an automated coil enzyme (CENZ) fluorometric method from the University of Rhode Island. That paper also presented an overview of the comparison between the two instruments, a description of the NASA Langley box model and the GEOS-Chem 3D global transport model [Millet et al., 2006], and an overview of the box model-TDLAS comparisons. The present study utilizes the TDLAS and box model results of the third paper by Fried et al. [2008] to (1) establish sets of conditions by which to distinguish "background" UT $\mathrm{CH}_{2} \mathrm{O}$ levels from those perturbed by convection and other causes; (2) quantify the $\mathrm{CH}_{2} \mathrm{O}$ precursor budgets for both air mass types; (3) quantify the fraction of time that the UT $\mathrm{CH}_{2} \mathrm{O}$ measurements over North America and the North Atlantic are perturbed during the summer of 2004; (4) provide estimates for the fraction of time that such perturbed $\mathrm{CH}_{2} \mathrm{O}$ levels are caused by direct convection of boundary layer $\mathrm{CH}_{2} \mathrm{O}$ and/or convection of $\mathrm{CH}_{2} \mathrm{O}$ precursors; (5) assess the ability of box models to reproduce the $\mathrm{CH}_{2} \mathrm{O}$ measurements given initial conditions supplied by the measurement suite; and (6) examine $\mathrm{CH}_{2} \mathrm{O}$ and $\mathrm{HO}_{2}$ relationships in the presence of enhanced NO.

\section{Modeled Temporal Dependence for Different Injection Scenarios in the UT}

[6] Understanding the cause of elevated $\mathrm{CH}_{2} \mathrm{O}$ in the UT (4th goal above) is of more than academic interest, as can be seen by the model runs of Figures 1 and 2. The Langley model was run forward in a time-dependent mode with chemical evolution of all species allowed after being initialized with median conditions observed from 8.5 to $9.5 \mathrm{~km}$ during INTEX-NA. The figures show resulting timedependent $\mathrm{CH}_{2} \mathrm{O}$ mixing ratios calculated from this "base" box model run (black curve) and for additional model runs assuming various injection scenarios of $\mathrm{NO}_{2}, \mathrm{CH}_{2} \mathrm{O}$ and its precursors starting at 12 noon (day 0.5). The initialization conditions for these perturbed runs are kept identical to those for the base run other than the injected species themselves. The blue curves in Figures 1 and 2 show results for direct injection of median observed continental boundary layer $\mathrm{CH}_{2} \mathrm{O}$ (2065 pptv). The dashed red curves show the results for injection of a suite of $\mathrm{CH}_{2} \mathrm{O}$ precursors $\left(\mathrm{CH}_{4}\right.$, MHP, $\mathrm{CH}_{3} \mathrm{OH}$, Acetone, and PAN) also based on median 

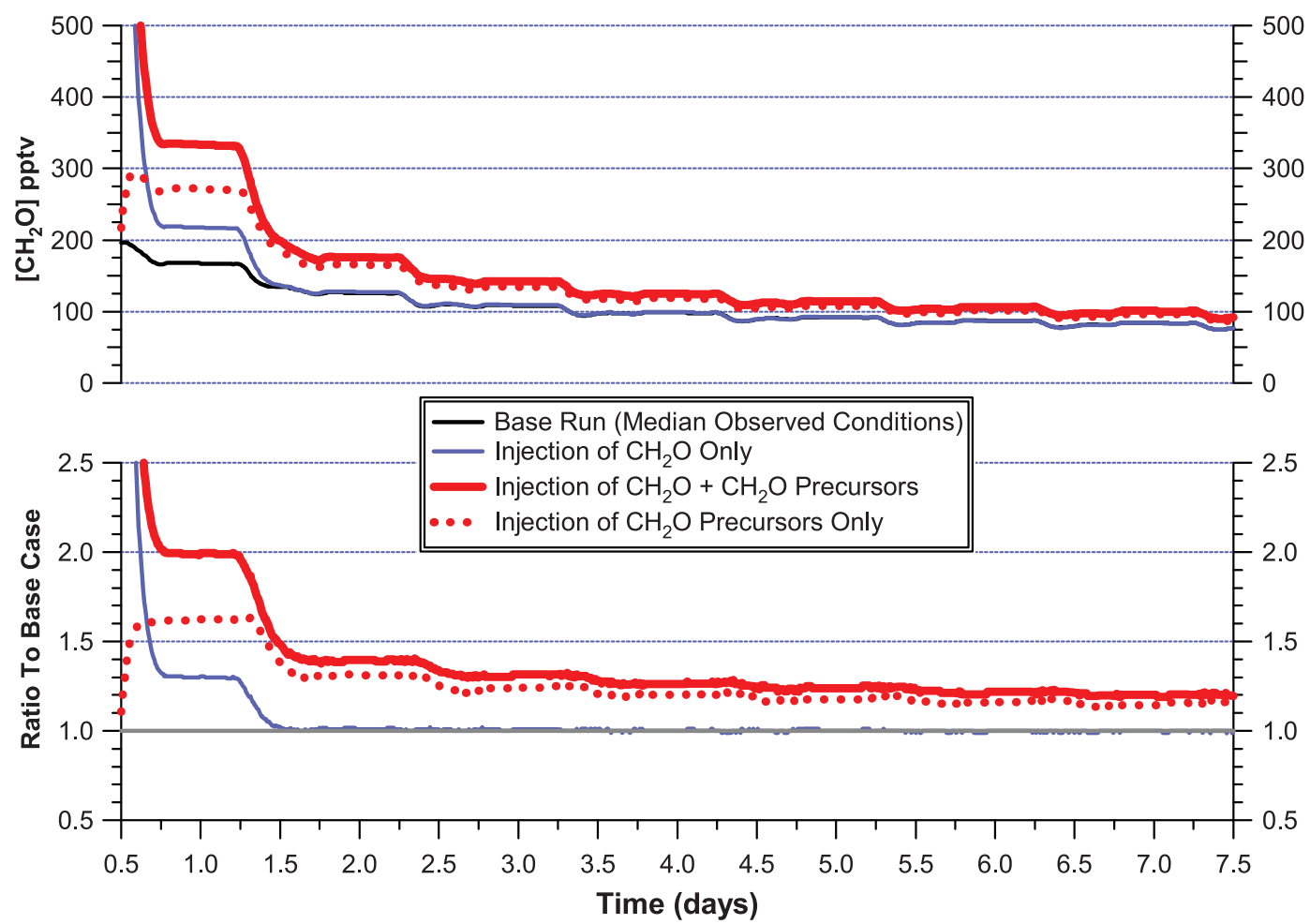

Figure 1. Box model runs for different scenarios at $9 \mathrm{~km}$. In the base run in all cases the model was run forward in a time-dependent mode for 7 days using observed median conditions and mixing ratios for $9 \mathrm{~km}(8.5-9.5 \mathrm{~km})$ as the initial conditions. The time-dependent $\mathrm{CH}_{2} \mathrm{O}$ mixing ratios were then calculated. The box model was then run using different injection scenarios starting at 12 noon based upon median mixing ratios from the continental boundary layer $\left(\left[\mathrm{CH}_{2} \mathrm{O}\right]=2065 \mathrm{pptv},\left[\mathrm{CH}_{4}\right]=1832 \mathrm{ppbv}\right.$, $[\mathrm{MHP}]=606 \mathrm{pptv},\left[\mathrm{CH}_{3} \mathrm{OH}\right]=3931 \mathrm{pptv},[$ Acetone $\left.]=1808 \mathrm{pptv},[\mathrm{PAN}]=330 \mathrm{pptv}\right)$. A median observed $9 \mathrm{~km}\left[\mathrm{NO}_{x}\right]$ mixing ratio of 345 pptv was input.

boundary layer mixing ratios, while the solid red curves show results for simultaneous injection of both $\mathrm{CH}_{2} \mathrm{O}$ and its precursors. The lower panel in each figure shows the results normalized to the base model run. Figure 1 shows simulations that assume an initial $\mathrm{NO}_{x}$ mixing ratio of $345 \mathrm{pptv}$ (obtained from median observed NO of $250 \mathrm{pptv}$ and a steady state calculation of $\mathrm{NO}_{2}$ ). Figure 2 shows results for the identical injection scenarios described in Figure 1, but with an additional initial $\mathrm{NO}_{x}$ injection source from lightning assumed here to equal 1 ppbv. In all cases, the model allows for photochemical decay of $\mathrm{NO}_{x}$ and the $\mathrm{CH}_{2} \mathrm{O}$ precursor species. The companion paper by Fried et al. [2008] discusses the importance of nitric oxide (NO) from sources such as lightning in accelerating the production of $\mathrm{CH}_{2} \mathrm{O}$ in the UT. This can be seen by comparing the precursor-only curves (dashed red lines) for the median and enhanced $\mathrm{NO}_{x}$ scenarios in Figures 1 and 2, respectively. One-half day after initialization (corresponding to 1 day in the plots), the $\mathrm{CH}_{2} \mathrm{O}$ is photochemically enhanced by $60 \%$ and $90 \%$ for the median and enhanced $\mathrm{NO}_{x}$ scenarios, respectively. Such enhanced NO accelerates the reaction of methylperoxy radicals $\left(\mathrm{CH}_{3} \mathrm{O}_{2}\right)$, and more generally $\mathrm{RO}_{2}$ radicals, in forming $\mathrm{CH}_{2} \mathrm{O}$ and $\mathrm{HO}_{2}$ in the process (Figure 3). As can be seen, the base case yields an initial $\mathrm{CH}_{2} \mathrm{O}$ mixing ratio of $195 \mathrm{pptv}$ in both figures and this rapidly decays with each diurnal cycle to mixing ratios $\sim 75 \mathrm{pptv}$ in 1 week. The direct injection of boundary layer $\mathrm{CH}_{2} \mathrm{O}$ decays to the base case $\sim 1$ day after the initial injection for both $\mathrm{NO}_{x}$ scenarios, after which it decays identically with the base case. By contrast, injection of $\mathrm{CH}_{2} \mathrm{O}$ precursors, either with $\mathrm{CH}_{2} \mathrm{O}$ or precursors alone yields elevated $\mathrm{CH}_{2} \mathrm{O}$ for up to one week in all cases. The injection of $\mathrm{CH}_{2} \mathrm{O}$ with precursors approaches injection of $\mathrm{CH}_{2} \mathrm{O}$ precursors alone after $\sim 1$ day in both $\mathrm{NO}_{x}$ scenarios. The effects of the additional $\mathrm{NO}_{x}$ on the $\mathrm{CH}_{2} \mathrm{O}$ plus precursor case is not realized until $\sim 1$ day downstream of the convective event, whereupon the elevated $\mathrm{NO}_{x}$ curve starts to diverge from the background $\mathrm{NO}_{x}$ case. After 1 week the elevation relative to the base case is $\sim 20 \%$ for the median $\mathrm{NO}_{x}$ simulations and $40 \%$ for the elevated $\mathrm{NO}_{x}$ simulations. Thus understanding the exact mechanism responsible for elevated $\mathrm{CH}_{2} \mathrm{O}$ in the UT is important for understanding its integrated influence and the extent of that influence downwind of convection. The base case plots in both $\mathrm{NO}_{x}$ scenarios also indicate that background $\mathrm{CH}_{2} \mathrm{O}$ in the UT over North America and the Atlantic Ocean should reside in the range between $75 \mathrm{pptv}$ and 195 pptv range for air masses up to one week old. Comparisons of these expectations with measurements will be presented in a later section. Throughout the rest of this paper all NO mixing ratios refer to calculations derived from measurements of $\mathrm{NO}_{2}$ [Bertram et al., 2007] assuming photostationary state. Although direct measurements of NO 


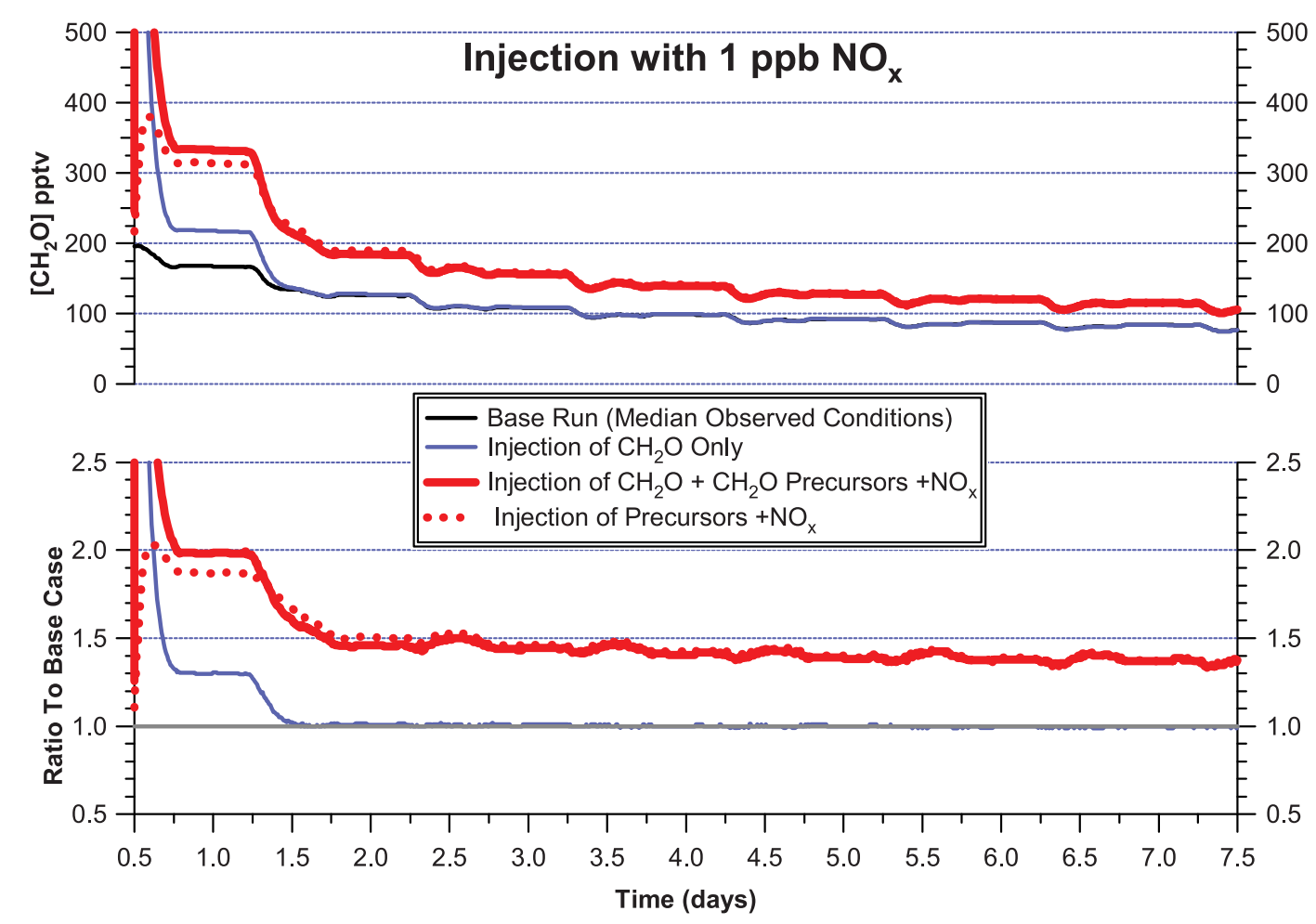

Figure 2. Same as Figure 1, only employing injection of 1 ppbv of $\mathrm{NO}_{x}$ input to the model at $9 \mathrm{~km}$.

were available, $\mathrm{NO}_{2}$-derived values generally provided more precise values [Ren et al., 2008].

\section{Measurement Box Model Comparisons for $\mathrm{CH}_{2} \mathrm{O}$ in the UT}

\subsection{Time Periods When Sampled Air Experienced Deep Convection and/or Lightning}

[7] The clear versus nonclear analysis in the companion paper by Fried et al. [2008] does not capture the many instances during INTEX-NA where convection affected UT $\mathrm{CH}_{2} \mathrm{O}$ mixing ratios during cloud-free conditions. Fuelberg et al. [2007] developed a methodology based upon a comparison of meteorological trajectory analysis with both Global Forecast System (GFS) modeled fields and data from the National Lightning Detection Network (NLDN) to identify convectively perturbed time periods. They produced estimates of when the sampled air mass had previously experienced deep convection or experienced lightning originating within $1.5^{\circ}$ latitude/longitude grid boxes. Although this procedure does not consider small scale processes such as turbulence that are not handled adequately by the GFS model, it does capture pollution events vertically lofted by processes that are resolvable by the GFS model. In the UT, $78 \%$ of the cloud encounters identified by Fried et $a l$. [2008], when time coincident TDLAS measurements and box models were available and where measurements of MHP were available for model input, experienced convective influence according to the Fuelberg et al. [2007] analysis. As convection is predominately a subgrid process, convective parameterization (CP) is needed to implicitly include its effects. The GFS CP [Global and Weather Modeling Branch, 2003] is a simplified version of the widely used Arakawa-Schubert scheme [Arakawa and
Schubert, 1974], which produces a convective quantitative precipitation forecast (QPF) as a by-product. Qualitative comparisons of the convective QPF with both lightning data from the NLDN and GOES satellite imagery indicate that our CP approach is appropriate for INTEX-NA. However, we recognize that the inherent constraints of both the CP approach [Arakawa and Schubert, 1974] and of the kinematic trajectories [Fuelberg et al., 1996; Stohl et al., 1995] results in generous spatial and temporal convective thresholds, which likely results in an overestimate of convective influence during INTEX-NA. Nevertheless, the remainder of this paper relies heavily on the Fuelberg et al. [2007] meteorological methodology as an indicator of convection.

[8] The companion paper by Fried et al. [2008] discussed the importance of MHP measurements in constraining box model calculations, particularly during fresh convection in the UT where model calculations of MHP do not accurately capture the observations. Throughout the rest of this paper all UT $\mathrm{CH}_{2} \mathrm{O}$ model values and measurement-model comparisons refer to time periods where MHP measurements are used in constraining the box model $(N=1188)$, unless explicitly stated otherwise. This includes MHP measurements at their limits of detection (LODs) where convective influence on MHP is not an issue.

\subsection{UT Measurement/Model Ratios}

[9] The companion paper by Fried et al. [2008] discussed comparisons between TDLAS measurements and box model $\mathrm{CH}_{2} \mathrm{O}$ values throughout the troposphere. As in that paper, all data here are from the 1-minute merged data set without segregation for ascending or descending flight legs. Of the 1188 comparisons points in the UT, $56 \%$ of the data fall within the combined random uncertainty estimates with $18 \%$ and $26 \%$ showing positive and negative outliers, 


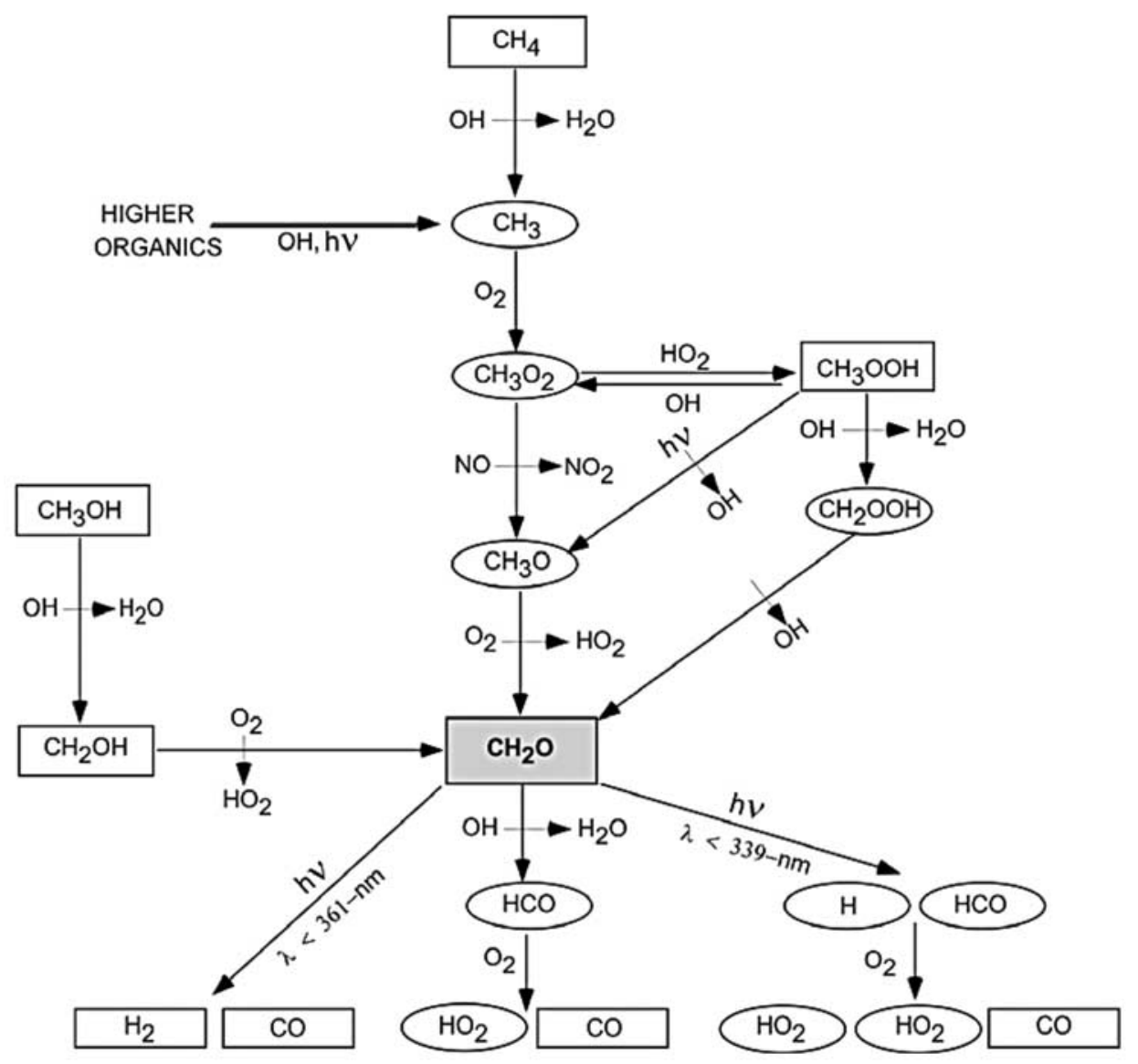

Figure 3. Production and destruction reactions for $\mathrm{CH}_{2} \mathrm{O}$ in the troposphere. Destruction from $\mathrm{NO}_{3}$ and the halogens are not shown nor is the production from organics with $\mathrm{Cl}$. Production of $\mathrm{CH}_{2} \mathrm{O}$ from higher organics, which in most cases proceed through the $\mathrm{CH}_{3}$ radical, are lumped together. Stable species are shown in boxes while reactive transients are shown in circles.

respectively. When systematic uncertainty estimates are considered, which encompasses uncertainties in the rate constants employed in the box model calculations, $62 \%$ of the UT comparisons fall within the combined systematic limits. Figure 4 displays UT measurement/box model ratios as a function of time since convection and time since first lightning encounter within $1.5^{\circ}$ latitude/longitude grid boxes from the Fuelberg et al. [2007] analysis. Of the convective and lightning-influenced points, the largest ratios are associated with such perturbations within 1 hour of sampling. It is entirely possible that these points reflect convection of unmeasured $\mathrm{CH}_{2} \mathrm{O}$ precursors with or without direct convection of boundary layer $\mathrm{CH}_{2} \mathrm{O}$; as Figure 1 shows these two effects become indistinguishable after $\sim 1$ day following the perturbation. However, large ratios also appear at other times, including those without convective or lightning influence (gray points in the center). Clearly other factors must be operative here as well as for many of the smaller ratios. In fact, only $32 \%$ of the UT outliers (ratios outside of the combined random uncertainty estimates) are influenced by convection and/or lightning within the past 6 hours and $58 \%$ of the UT nonoutliers experienced convection and/or lightning within the past 6 hours. Thus with the exception of the largest outliers associated with very recent perturbations from convection and/or lightning, UT air masses impacted by these perturbations generally are not well correlated with the $\mathrm{CH}_{2} \mathrm{O}$ measurement-model agreement. This likely reflects the fact that we generally have accurate measurements of the convected precursors that are used in the model, and hence the box model is able to capture perturbations to the $\mathrm{CH}_{2} \mathrm{O}$ production. This of course requires model constraint using measurements of MHP. For example, during fresh convection (sampling within $\sim 6$ hours of the convective event) the median UT measurement/model ratio was 1.04 where the model was constrained by MHP measurements. This compares to a median ratio of 1.63 where modeled MHP values were used for the same comparison points. Here MHP was calculated from methane and other organics. It is also possible that some of the convected air, indicated by the meteorological analysis, was transported from midaltitudes, where in all likelihood there is minimal elevation in $\mathrm{CH}_{2} \mathrm{O}$ and/or its precursors. Furthermore, it is also possible that fresh convection in many cases may be transported with air that is well-aged since time of emission, and depending upon the particular $\mathrm{CH}_{2} \mathrm{O}$ source(s) that are present, the box model may or may not faithfully capture such observations. Lastly, as no trajectory model is perfect, as was previously discussed, one can encounter errors in the exact placement of convection, and these increase with time since convec- 


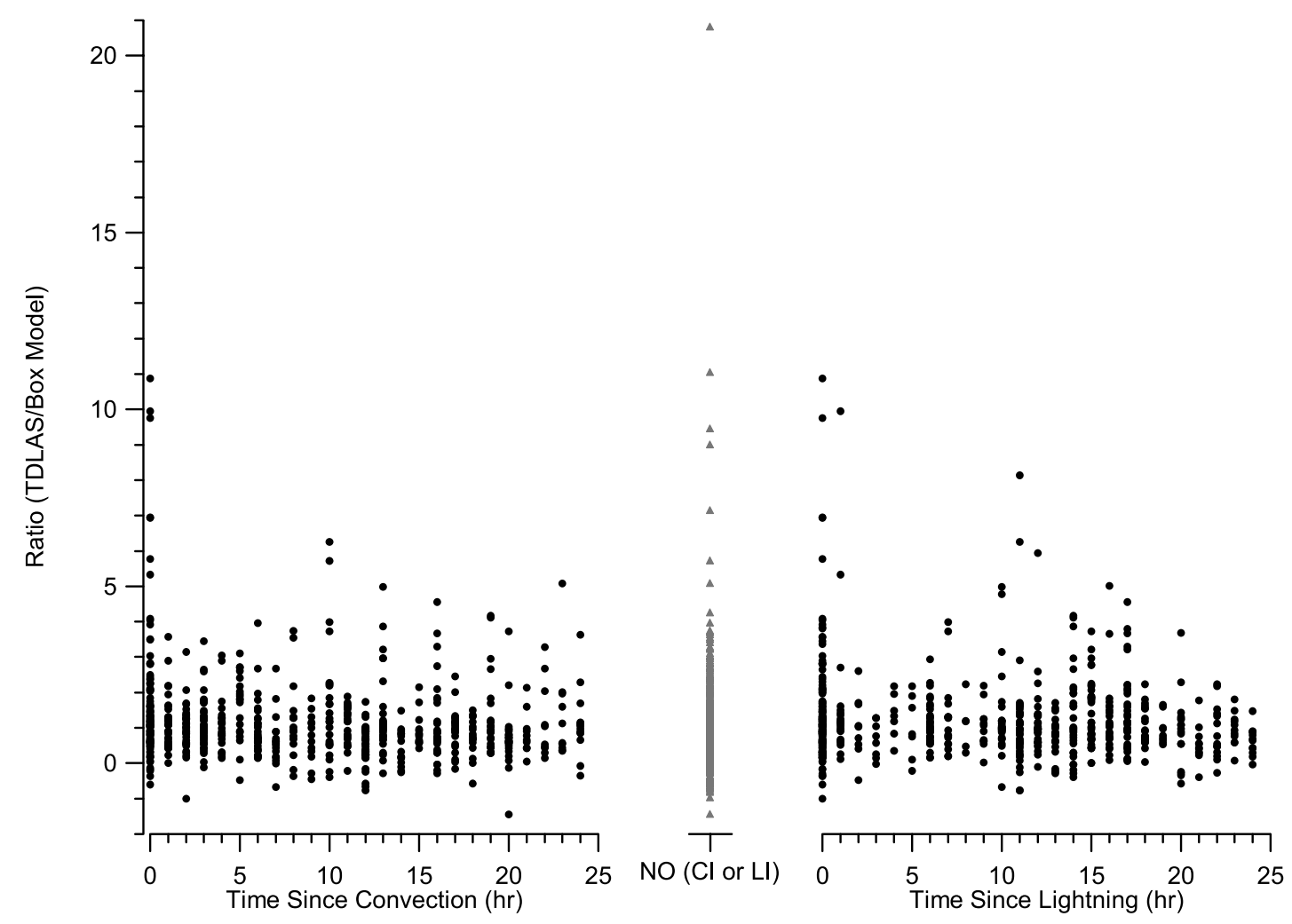

Figure 4. TDLAS/Box model ratios for time coincident 1-minute merged data (all data where MHP used as a model constraint, including ascents and descents) as a function of time since convection and time since lightning in the UT from the Fuelberg et al. [2007] analysis. The gray points in the middle reflect ratios where there is no convective or lighting influence, NO (CI or LI), from this analysis. These points constitute $47 \%$ of the UT measurement-model comparisons. The largest ratio $(R=20.8)$ in this category is suspect since it is based upon TDLAS measurements comprising only $5 \%$ of the 1 -minute comparison period.

tion. The case studies in section 7 will further elucidate various measurement-model behaviors for different convection scenarios.

\section{Background and Perturbed $\mathrm{CH}_{2} \mathrm{O}$ Levels in the UT}

[10] As was pointed out previously, transport of $\mathrm{CH}_{2} \mathrm{O}$ precursors can occur simultaneously with direct transport of $\mathrm{CH}_{2} \mathrm{O}$ to the UT as well. These two effects become indistinguishable after $\sim 1$ day following the convection, and as shown in Figure 1, behave like convection of $\mathrm{CH}_{2} \mathrm{O}$ precursors only, which can yield significant perturbations out to 1 week or more. We thus provide estimates in this section for the percentage of time $\mathrm{UT} \mathrm{CH}_{2} \mathrm{O}$ perturbations are associated with precursors, without distinguishing if direct transport of $\mathrm{CH}_{2} \mathrm{O}$ is simultaneously present.

[11] To accomplish this we first determine a set of background conditions for the UT over North America and the Atlantic Ocean during summer months. This is based upon a variety of tracers, both $\mathrm{CH}_{2} \mathrm{O}$ precursors and anthropogenic pollution tracers. These tracers are listed in Table 1 along with threshold values, obtained from their respective UT mixing ratios at the 25 percentile level for all measurements during INTEX-NA (not restricted to geographic location or time periods when TDLAS measure- ment and/or box model results are present). In many cases not all the tracers were present in the data set due to the intermittent sampling of the appropriate measurement system. In this analysis we required that at least three of the ten tracers be present and those that were present all had to be less than or equal to their respective threshold values for an air mass to be characterized as "background." Despite the fact that this $25 \%$ cutoff limit is somewhat arbitrary, it is important to note that many of the background tracer levels were in fact below their 10 percentile UT levels. This vetting process resulted in 81-aged clean background UT time periods, which are hereafter referred to as "background" time periods. Figure 5 displays the resulting $\mathrm{CH}_{2} \mathrm{O}$ TDLAS measurements $(N=60)$, box model results $(N=31)$, CENZ measurements $(N=11)$, and GEOS-Chem three-dimensional model results $(N=81)$ for these UT time periods. As indicated by the inset, background air masses in the UT were sampled at various locations over North America and the Atlantic Ocean. The shaded region (-61 to 165 pptv) highlighted in Figure 5 captures most of the background measurements and model results for the 6$12 \mathrm{~km}$ UT range. Although the precise upper limit has an uncertainty of $\sim 15 \%$, the present upper limit of $165 \mathrm{pptv}$ captures $98 \%$ of the TDLAS measurements and $100 \%$ of the box model results and excludes some of the clear outlier points, which are primarily from the GEOS-Chem model; 6 


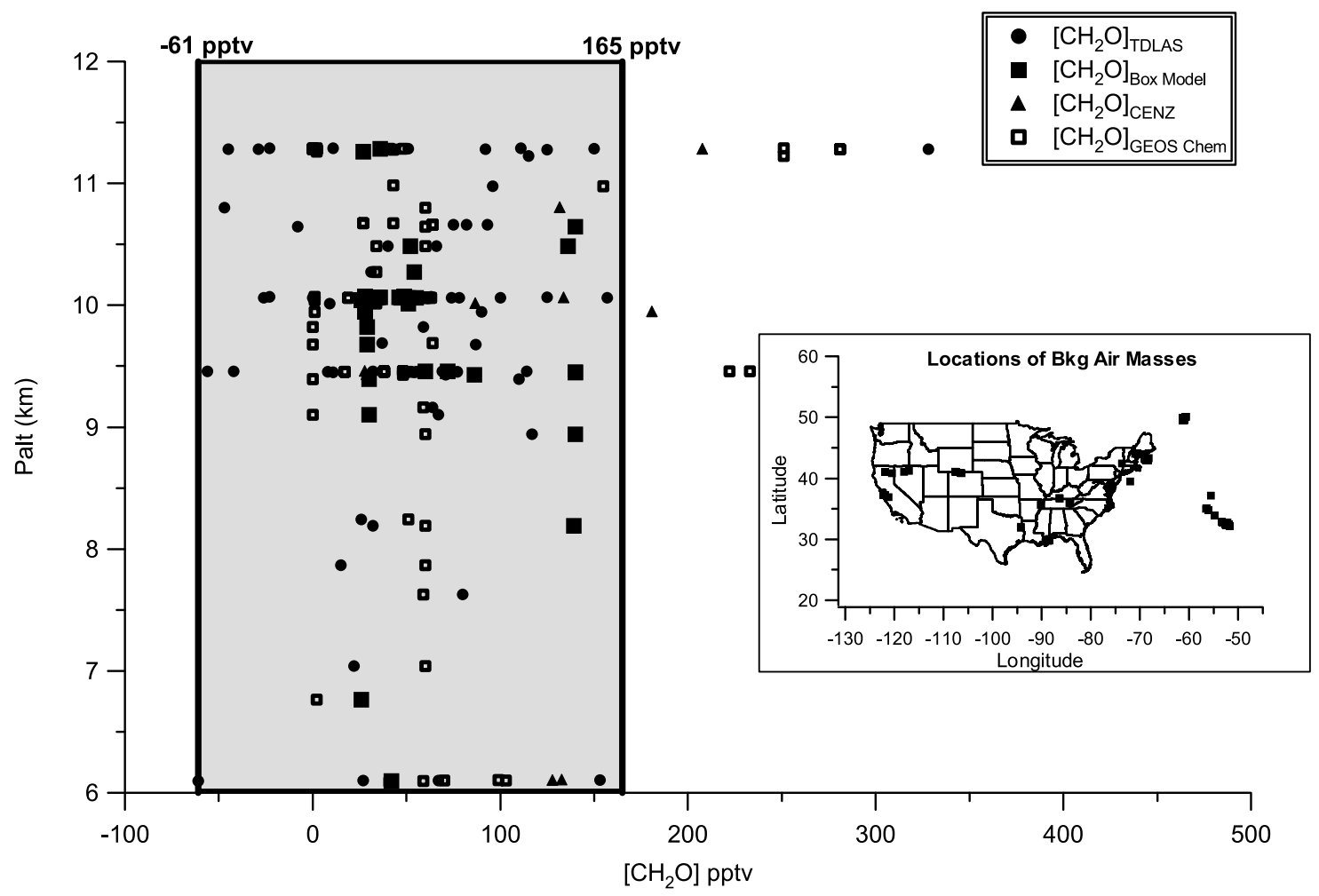

Figure 5. Background UT measurements and model results ( $N=60$ for TDLAS; $N=31$ for Box model; $N=11$ for CENZ; and $N=81$ for GEOS-Chem) satisfying the threshold criteria of Table 1 and further discussed in the text. The limits of $-61 \mathrm{pptv}$ to $165 \mathrm{pptv}$ were determined using the various criteria discussed in the text, and the shaded region encompassing these limits captures $98 \%$ of the TDLAS measurements and $100 \%$ of the box model results in the UT. The inset depicts the geographic location where these samples were acquired. The measurements and model results are from the 1-minute merged data set and are not time coincident. The near zero GEOS-Chem values are all associated with points on the same day during a continuous 13-minute flight leg. These values, which are at least 50 pptv lower than values close in time, appear to be caused by a minor deposition sink employed in the model.

of the GEOS-Chem model results lie outside the 165 pptv limit while only two CENZ measurements lie outside this limit. A distribution plot of all UT box model results reveals two distributions with the second distribution starting to dominate between 150 and 170 pptv, a range that is consistent with the background threshold value above. Furthermore, the background $\mathrm{CH}_{2} \mathrm{O}$ levels of Figure 5 ( -61 to $165 \mathrm{pptv})$ are consistent with the base run levels of Figures 1 and 2; in the absence of perturbations caused by convection and other causes, the time-dependent model calculations in these figures are close to the background levels of Figure 5 at the start of the calculation (195 pptv) and fall within the background range of Figure 5 after only $\sim 6$ hours of decay. Based upon the median measurements and box model values of Figure 5 (range: 47 to $61 \mathrm{pptv}$ ) the time-dependent calculations suggest a median air mass age of at least 7.5 days for these UT background air masses.

[12] Figure 6 displays all the TDLAS, and CENZ measurements and box model results acquired in the $6-12 \mathrm{~km}$ UT range during INTEX-NA for all data in the database not parsed by location, nor restricted for time coincidence and/ or the availability of MHP for model input. The (-61 to 165 pptv) background limits defined above are superimposed on these plots to emphasize in all three cases: (1) the large number of points falling within the background range (to be discussed) and (2) the large number of perturbed UT observations outside this range, the percentages for which are indicated in the plots for all three cases. Out of a total of 2906 TDLAS measurements of $\mathrm{CH}_{2} \mathrm{O}$ in the UT, $46 \%$ lie outside the positive upper background limit. This compares to $42 \%$ and $38 \%$, respectively, for the box model and CENZ measurements. The GEOS-Chem model results, which are not shown, indicate that $40 \%$ of the results fall outside the background limits. Taken together, all 4 data sets indicate that $\sim 40 \%$ of the UT observations and/or model results for $\mathrm{CH}_{2} \mathrm{O}$ reveal perturbations relative to background conditions (i.e., exceed the $165 \mathrm{pptv}$ upper bound for background conditions). These perturbations include convectively influenced air both with and without biomass burning influence. Even though Figure 6 is not restricted for time coincidence, many of the perturbations appear to be common to all three data sets; the perturbations around $10.7 \mathrm{~km}, 10 \mathrm{~km}, 9.3 \mathrm{~km}$, and $7 \mathrm{~km}$ are examples of this.

[13] Averaged over the entire UT 6-12 km range, $70 \%$ of the perturbed elevated TDLAS measurements (TDLAS > 165 pptv, where MHP is used to constrain the box model) have elevated box model production rates associated with $\mathrm{CH}_{2} \mathrm{O}$ precursor transport. Here we define elevated box 
Table 1. Tracer Species and Their Lowest 25 Percentile Mixing Ratio Thresholds in the UT $(6-12 \mathrm{~km})$ Used to Determine Background Conditions ${ }^{\mathrm{a}}$

\begin{tabular}{clc}
\hline Species Number & Species & Mixing Ratio \\
\hline 1 & $\mathrm{CH}_{4}$ & 1.779 \\
2 & Ethane & 549 \\
3 & Ethyne & 62 \\
4 & Benzene & 7 \\
5 & $\mathrm{C}_{2} \mathrm{Cl}_{4}$ & 2.6 \\
6 & Methanol & 792 \\
7 & Benzene & 16 \\
8 & $\mathrm{MHP}$ & 20 \\
9 & $\mathrm{CO}$ & 83 \\
10 & $\mathrm{UCN}$ & 579 \\
\hline
\end{tabular}

${ }^{a}$ All mixing ratios are in pptv with the exception of $\mathrm{CH}_{4}, \mathrm{CO}$, and $\mathrm{UCN}$ (ultra fine aerosol number density in the $3-10 \mathrm{~nm}$ size bins) which are in ppmv, ppbv, and particles $\mathrm{cm}^{-3}$, respectively. Measurements at their limit of detection (LOD) were included in this analysis by assigning the LOD to the mixing ratio. Species 1-5: from Univ. California Irvine air collection/ GC-MS system; species 6-7: from the NASA Ames PANAK system; species 8: from URI CENZ system; species 9: from the NASA Langley DACOM TDL system; species 10: from the University of Hawaii aerosol system.

model production rates as those higher than the maximum background $\mathrm{CH}_{2} \mathrm{O}$ production rates for the three UT altitude bins expressed in pptv $\mathrm{sec}^{-1}\left(6-8 \mathrm{~km}: 0.028 \mathrm{pptv} \mathrm{sec}^{-1}\right.$; $8-10 \mathrm{~km}: 0.022$ pptv sec $^{-1}$; 10-12 km: 0.027 pptv sec $^{-1}$ ). Expressing the production rates this way is necessary to account for the changing number density with altitude. Parsing the UT range into the three altitude bins, we find that $67 \%, 80 \%$, and $53 \%$ of the elevated TDLAS measure- ments are associated with enhanced model production rates for respectively the $6-8 \mathrm{~km}, 8-10 \mathrm{~km}$, and $10-12 \mathrm{~km}$, altitude ranges. Since the box model does not simulate transport, model $\mathrm{CH}_{2} \mathrm{O}$ production rates are unaffected by direct convection of $\mathrm{CH}_{2} \mathrm{O}$ from lower altitudes.

[14] In a second determination, we employ the convective products from Fuelberg et al. [2007]. In this approach, we deduce the fraction of the perturbed UT TDLAS measurements (measurements $>165$ pptv) that show convective influence from the Fuelberg et al. [2007] analysis greater than a certain characteristic time since convection. This approach relies on the fact that after this characteristic time, direct convection of $\mathrm{CH}_{2} \mathrm{O}$ from lower altitudes quickly decays to background levels due to the short $\mathrm{CH}_{2} \mathrm{O}$ lifetime, as is shown by Figure 1. We determined this characteristic time using expressions (1) and (2) below. Expression (1), which is derived by Bertram et al. [2007], relates the UT mean mixing ratio for a species in fresh convective outflow at time zero $\left(\left[\mathrm{CH}_{2} \mathrm{O}\right]_{\mathrm{UT}}(\mathrm{t}=0)\right.$ ) to the fraction (f) of the boundary layer air present in the fresh convection and the UT mixing ratio in the background air $\left(\left[\mathrm{CH}_{2} \mathrm{O}\right]_{\mathrm{UT}}\right)$ in accordance with:

$$
\left[\mathrm{CH}_{2} \mathrm{O}\right]_{\mathrm{UT}(\mathrm{t}=0)}=\mathrm{f}\left[\mathrm{CH}_{2} \mathrm{O}\right]_{\mathrm{BL}}+(1-\mathrm{f})\left[\mathrm{CH}_{2} \mathrm{O}\right]_{\mathrm{UT}}
$$

[15] Using a value of $\mathrm{f}=0.20 \pm 0.1$, determined by Bertram et al. [2007], a median TDLAS measured value of 61 pptv for background air determined from Figure 5, a median TDLAS boundary value of 2065 pptv, we determine

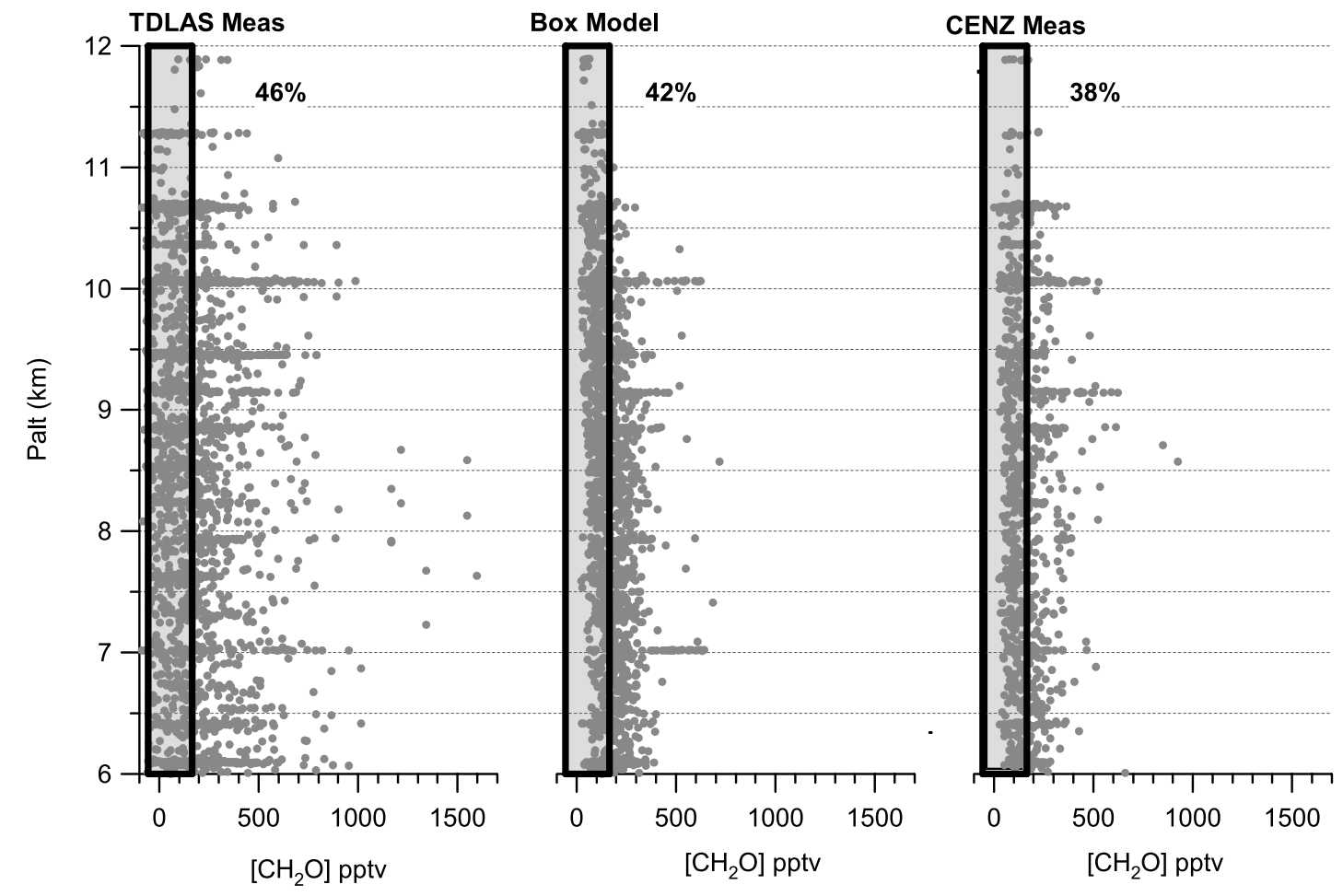

Figure 6. TDLAS, Box model, and CENZ results in the 6-12 km UT range for all 1-minute merged data not restricted to location, time coincidence, or MHP measurements available for model input. The ( -61 to $165 \mathrm{pptv}$ ) background limits defined in the text are indicated on these plots in the shaded regions within the dark rectangles. Indicated with each plot are the percentages of the total UT observations or model results exceeding the 165 pptv background limit. 
a value of $462 \pm 231$ pptv for $\left[\mathrm{CH}_{2} \mathrm{O}\right]_{\mathrm{UT}}(\mathrm{t}=0)$. During daylight hours, the time $(t)$ for this fresh direct boundary layer $\mathrm{CH}_{2} \mathrm{O}$ convection to decay to the background threshold value of $165 \mathrm{pptv} \pm\left[\mathrm{CH}_{2} \mathrm{O}\right]_{\mathrm{Bkg}}$ Threshold $)$ is determined by:

$$
\left[\mathrm{CH}_{2} \mathrm{O}\right]_{\mathrm{Bkg} \text { Threshold }}=(462 \pm 231) \exp -(t / \tau)
$$

[16] Using a median midday UT $\mathrm{CH}_{2} \mathrm{O}$ lifetime $(\tau)$ of 1.5 hours we determine a characteristic time $t$ of 1.5 hours (range 0.5 to 2 hours) for the time it should take for the average fresh convective outflow in the UT to decay below the background threshold level. Perturbed UT $\mathrm{CH}_{2} \mathrm{O}$ observations whose time since convection are greater than 1.5 hours can be ascribed to in situ production of $\mathrm{CH}_{2} \mathrm{O}$ from its precursors. Of the TDLAS $\mathrm{CH}_{2} \mathrm{O}$ observations (where there are measurements of MHP to constrain the box model, and where there is convective influence) in perturbed UT air, 73\% fall in this category. This value is in reasonable agreement with the $70 \%$ value determined by elevated model production rates. This suggests that any potential errors due to overestimating the convective influence, as discussed previously, must be small. For the remaining $27 \%$ to $30 \%$ of the time, perturbed UT observations by TDLAS can be ascribed to direct $\mathrm{CH}_{2} \mathrm{O}$ convection with or without convection of $\mathrm{CH}_{2} \mathrm{O}$ precursors. At present there is no way to pull these two effects apart, and thus $\mathrm{CH}_{2} \mathrm{O}$ precursors may be playing an even larger role in the UT. The one drawback of the present analysis is that it assumes a $\mathrm{CH}_{2} \mathrm{O}$ lifetime of 1.5 hours, which is characteristic of midday. Convection at time periods later in the day or during the previous night would yield longer characteristic times with a consequent lower value for the precursor percentage. Fortunately the local sun time when most of the convection during INTEX-NA was sampled (for time coincident measurement and box model periods) was between 12 noon and $1 \mathrm{PM}$, and thus the error from this cause is small in most cases. This procedure is also not that sensitive to the precise background cutoff limit. If the true background cutoff limit for $\mathrm{CH}_{2} \mathrm{O}$ is 100 pptv instead of $165 \mathrm{pptv}$, this would only change the precursor percentage determination from $73 \%$ to $74 \%$. A 200 pptv cutoff limit changes this $72 \%$. We also used the above procedure to determine the perturbation percentage due to precursors broken out for the three different altitude bins in the UT and this yields the following: $72 \%$ for $6-8 \mathrm{~km}, 72 \%$ for $8-10 \mathrm{~km}$, and $80 \%$ for $10-12 \mathrm{~km}$.

[17] As discussed in the companion paper by Fried et al. [2008], the meteorological analysis from Fuelberg et al. [2007] indicates that 2004 was a record breaking year for wildfire activity in northwest Canada and Alaska and these plumes were sampled by the DC- 8 on numerous flights. Although this can perturb the chemistry of the UT, we are more interested in the present study in characterizing the more ubiquitous UT perturbations from convection. To accomplish this we use PAN, $\mathrm{HCN}, \mathrm{CH}_{3} \mathrm{CN}$, and $\mathrm{CO}$ as tracers of fire plumes. Specifically, we have identified cases where these 4 tracers exceeded their UT 99th percentile values of PAN (951 pptv), $\mathrm{HCN}$ (755 pptv), $\mathrm{CH}_{3} \mathrm{CN}$ (306 pptv), and CO (219 ppbv). For example, during the July 18 Alaskan fire plume intercept shown in Figure $5 \mathrm{~b}$ of the companion paper by Fried et al. [2008] at $7 \mathrm{~km}$, these 4 fire plume tracers attained values as high as 1574 pptv for PAN, 2740 pptv for $\mathrm{HCN}, 1318$ pptv for $\mathrm{CH}_{3} \mathrm{CN}$, and $400 \mathrm{ppbv}$ for $\mathrm{CO}$. After removing the few UT points that are clearly affected by fire plumes, the above percentages for transport of $\mathrm{CH}_{2} \mathrm{O}$ precursors are negligibly changed by less than $1 \%$ for all 3 altitude bins.

\section{UT Budgets for Production of $\mathrm{CH}_{2} \mathrm{O}$ During Background and Perturbed Periods}

[18] An examination of Figure 6 immediately reveals that there are a significantly larger number of measurements and box model results that fall within the UT background limits than indicated by the strict 81 time periods discussed above. For example, as shown in Figure 5, there are 60 TDLAS measurements that satisfy the strict background limit, yet there are a total of 1579 UT TDLAS measurements with $\mathrm{CH}_{2} \mathrm{O}$ levels less than the 165 pptv background limit. In the case of the box model and CENZ measurements, 1320 and 717 points, respectively, satisfy this criterion. In some cases there are not enough tracers available, while in other cases elevated longer-lived tracers are still present but the air mass is sufficiently well-aged to allow decay of $\mathrm{CH}_{2} \mathrm{O}$ down to background levels. Rather than restrict our discussion of UT $\mathrm{CH}_{2} \mathrm{O}$ budgets to a small number of air masses obeying the strict background limit (there are only 24 time coincident TDLAS and box model results in this category), we employ here a less rigorous surrogate definition for background and perturbed UT cases based upon modeled $\mathrm{CH}_{2} \mathrm{O}$ levels. Air masses where the time coincident $\mathrm{CH}_{2} \mathrm{O}$ mixing ratios for the box model results are equal to or below 165 pptv will henceforth be classified as background (49\% of UT time coincident comparisons), regardless of the tracer levels in Table 1, and those where the model exceeds this limit are classified as perturbed (51\% of UT time coincident comparisons).

[19] Table 2 compiles the mean, standard deviation, median, and number of time coincident TDLAS and box model results for the $6-8 \mathrm{~km}, 8-10 \mathrm{~km}$, and $10-12 \mathrm{~km}$ pressure altitude bins in the UT for the background and perturbed air masses as defined above. In the $10-12 \mathrm{~km}$ range for the perturbed case, there were 27 additional time periods where the NO mixing ratios were all larger than 1000 pptv, the box model values were below the 165 pptv cutoff limit, and in most cases the measured $\mathrm{CH}_{2} \mathrm{O}$ values were all above this limit. These 27 points were added to the original 42 perturbed comparison points, and account for the fact that the box model and observations diverge under high $\mathrm{NO}_{x}$ conditions. This will be further discussed in section 6 . Elevated $\mathrm{NO}_{x}$, which is caused by convection, lightning, and potentially stratospheric intrusions, enhances $\mathrm{CH}_{2} \mathrm{O}$ production (see Figure 3 ). Only perturbed time periods in the 10-12 altitude bin were affected by this. Without this correction, the median point-by-point measurement/box model ratio $(\mathrm{R})$ also shown in this table would be erroneously lowered from 1.3 to 1.2 . Considering only NO mixing ratios greater than $1000 \mathrm{pptv}$ in the $10-12 \mathrm{~km}$ perturbed bin, the median measurement/model ratio increases to 1.8. Table 2 also displays the $\mathrm{NO}_{x}$ mixing ratios.

[20] Our background/perturbed segregation approach has ambiguities in cases (1) where the measurements are per- 
Table 2. Statistics for Time Coincident $\mathrm{CH}_{2} \mathrm{O}$ TDLAS and Box Model Results for the Three Altitude Bins in the 6-12 km $P_{\text {alt }}$ Range (in km) for all Locations During INTEX-NA ${ }^{\mathrm{a}}$

\begin{tabular}{ccccccccccc}
\hline & \multicolumn{3}{c}{ TDLAS } & & \multicolumn{3}{c}{ Box Model } & & \\
\cline { 2 - 4 } \cline { 6 - 8 }$P_{\text {alt }}$ Range & Average & Median & $N$ & & Average & Median & $N$ & $R$ & {$\left[\mathrm{NO}_{x}\right]$} \\
\hline $6-8$ & $156 \pm 205$ & 104 & 153 & & $119 \pm 31$ & 125 & 153 & 0.89 & 68 \\
$\mathbf{6 - 8}$ & $\mathbf{2 5 4} \pm \mathbf{2 0 2}$ & $\mathbf{2 1 1}$ & $\mathbf{3 1 4}$ & & $\mathbf{2 6 4} \pm \mathbf{1 0 0}$ & $\mathbf{2 3 7}$ & $\mathbf{3 1 4}$ & $\mathbf{0 . 8 6}$ & $\mathbf{1 0 3}$ \\
$8-10$ & $131 \pm 178$ & 90 & 237 & & $108 \pm 37$ & 113 & 237 & 0.92 & 269 \\
$\mathbf{8}-\mathbf{1 0}$ & $\mathbf{2 6 8} \pm \mathbf{2 0 8}$ & $\mathbf{2 1 2}$ & $\mathbf{2 4 5}$ & & $\mathbf{2 5 0} \pm \mathbf{7 3}$ & $\mathbf{2 3 0}$ & $\mathbf{2 4 5}$ & $\mathbf{0 . 9 6}$ & $\mathbf{3 9 6}$ \\
$10-12$ & $95 \pm 114$ & 68 & 170 & $99 \pm 37$ & 99 & 170 & 0.72 & 548 \\
$\mathbf{1 0}-\mathbf{1 2}$ & $\mathbf{3 3 7} \pm \mathbf{2 1 2}$ & $\mathbf{2 9 3}$ & $\mathbf{6 9}$ & $\mathbf{2 3 0} \pm \mathbf{1 5 0}$ & $\mathbf{1 9 0}$ & $\mathbf{6 9}$ & $\mathbf{1 . 3 4}$ & $\mathbf{1 3 9 1}$ \\
\hline
\end{tabular}

${ }^{a}$ Background time periods (where Box model results are $\leq 165$ pptv) are shown in the first row of each altitude bin while the perturbed time periods (where Model > $165 \mathrm{pptv}$ ) are highlighted in bold face in the second row of each altitude bin. All mixing ratios are in pptv, and the standard deviations are indicated with the averages. In the $10-12 \mathrm{~km}$ range, 27 additional points were added to the perturbed periods where NO mixing ratios $>1000$ pptv (see text for a description of the rational for this). This data set is based on the 1188 comparison points where MHP measurements are used in the model constraint. The term $\mathrm{R}$ represents the median point-by-point measurement/Box model ratio for the particular air mass. Also shown are the median $\mathrm{NO}_{x}$ mixing ratios for each category from the steady state calculated $\mathrm{NO}$ and measurements of $\mathrm{NO}_{2}$. For reference, the median continental boundary layer $\mathrm{CH}_{2} \mathrm{O}$ and $\mathrm{NO}_{x}$ mixing ratios are 2065 and 278 pptv, respectively.

turbed (TDLAS $>165$ pptv) relative to background box model results ( $28 \%$ of the UT time coincident comparisons) and (2) alternatively where the measurements fall in the background range while the model results are perturbed (35\% of the comparisons). The first, as discussed above, tends to deemphasize the magnitude of the convective perturbations. Data in the second category, which includes data affected by uptake, would do the opposite. Despite these caveats this segregation approach provides a useful way to contrast $\mathrm{CH}_{2} \mathrm{O}$ production terms for perturbed and background air masses.

[21] As shown in Table 2, the median TDLAS and box model mixing ratios are comparable for all cases with the exception of the perturbed $10-12 \mathrm{~km}$ bin. With the exception of this bin, the point-by-point TDLAS/Box Model ratios range between 0.72 and 0.96 and the differences (not shown, TDLAS-Box Model) range between -10 and $-31 \mathrm{pptv}$. For the perturbed $10-12 \mathrm{~km}$ altitude case, the median point-by-point difference is slightly elevated $(64 \mathrm{pptv})$ relative to the other cases $($ ratio $=1.34)$. Here the median $\mathrm{NO}_{x}$ levels are significantly elevated (1391 pptv) relative to the other cases. This will be further discussed in section 6 .

[22] During the UTOPIHAN II campaign, Stickler et al. [2006] measured UT $\mathrm{CH}_{2} \mathrm{O}$ background mixing ratios in the range between $\sim 25 \mathrm{pptv}$ and $150 \mathrm{pptv}$ at $\sim 8 \mathrm{~km}$ during one flight on 19 July 2003. During a second flight on 16 July 2003 at $\sim 8 \mathrm{~km}$, identified by these authors as convectively influenced, the $\mathrm{CH}_{2} \mathrm{O}$ mixing ratios attained values as high as $\sim 1000$ pptv and averaged around $300 \mathrm{pptv}$. Both mixing ratios are similar in magnitude to those of the present study. Kormann et al. [2003] during the summer of 2001 MINOS campaign over the eastern Mediterranean also identified time periods where UT $\mathrm{CH}_{2} \mathrm{O}$ mixing ratios were reflective of the air mass origin. One air mass in particular on 16 August 2001 was identified as originating from the western Atlantic Ocean and produced mean background $\mathrm{CH}_{2} \mathrm{O}$ mixing ratios ranging between 114 and $281 \mathrm{pptv}$ for the 6- to $12-\mathrm{km}$ altitude range. Although somewhat higher than our background levels, the lower limit falls within the range of values observed in this study. During a second flight by Kormann et al. [2003] on 3 August 2001, where the air originated from Indian monsoon outflow, the mean UT $\mathrm{CH}_{2} \mathrm{O}$ levels ranged between 703 to $1276 \mathrm{pptv}$. Although this is considerably higher than the perturbed means shown in Table 2, such measurements are within the perturbed UT range ( -88 to 1549 pptv not shown) observed in this study.

[23] Figure 7 plots the median $\mathrm{UT}_{\mathrm{CH}_{2} \mathrm{O} \text { production rates }}$ (in pptv $\mathrm{sec}^{-1}$ ) for time coincident TDLAS and box model results where MHP measurements are used in the model constraint. The production rates are from the box model runs for the major production terms only. Contributions from alkenes, alkanes, isoprene, ethene, aromatics, acetic acid, and acetaldehyde are calculated but are too low to be included in this figure. This plot shows the data parsed into background and perturbed air masses, as defined above, for each of the three altitude bins in the UT. The production rates are for the parent species shown. The reaction between $\mathrm{CH}_{3} \mathrm{O}_{2}$ and $\mathrm{NO}$ is the major source of $\mathrm{CH}_{2} \mathrm{O}$, and $\mathrm{CH}_{3} \mathrm{O}_{2}$ itself is formed by oxidation of a wide range of species, including $\mathrm{CH}_{4}$. The contributions to $\mathrm{CH}_{2} \mathrm{O}$ production from this reaction were partitioned and ascribed to the various source species using the model steady assumption for $\mathrm{CH}_{3} \mathrm{O}_{2}$. The PAN term includes PAN and reactions for $\mathrm{RCO}_{3}$ type compounds. The ketones term includes acetone as well as other ketones. The numbers above each component represent the production percentage for that air mass type in the given altitude bin. The percentages for the major species shown comprise $83 \%$ to $92 \%$ of the total $\mathrm{CH}_{2} \mathrm{O}$ production.

[24] As can be seen in Figure 7, in all cases $\mathrm{CH}_{2} \mathrm{O}$ production from $\mathrm{CH}_{4}$ is the major term, even in perturbed air masses on average. In general, this is followed by production from $\mathrm{MHP}\left(\mathrm{CH}_{3} \mathrm{OOH}\right), \mathrm{MeOH}$ (methanol), PANS, and ketones. The total $\mathrm{CH}_{2} \mathrm{O}$ production rate expressed in mixing ratio per unit time as a function of altitude has a number of competing terms. On one hand the production rate should drop off with altitude due to the strong temperature dependence $\mathrm{CH}_{4}+\mathrm{OH}$; there is a factor of 2 drop in this reaction rate in the $10-12 \mathrm{~km}$ bin compared to the $6-8 \mathrm{~km}$ bin. This is countered by a factor of $\sim 1.5$ to 1.7 increase in $\mathrm{OH}$ number density and over an order of magnitude increase in NO between these two altitudes. As can be seen in Figure 7, in the background cases these effects offset and the total $\mathrm{CH}_{2} \mathrm{O}$ production rates are essentially constant with altitude. For the perturbed cases there is a slight change with altitude (factor of $12 \%$ for the two altitudes in question) due to enhanced $\mathrm{NO}, \mathrm{OH}$, and methanol with altitude. In the case of the latter, the median methanol increases from 1937 to 2423 pptv from the lowest to the highest altitude bins. The total production rates are over a factor of 2 higher in perturbed cases relative to background at all altitudes.

[25] The enhanced $\mathrm{NO}$ with altitude in part reflects the fact that both perturbed and background air masses in the UT are in many cases influenced by lightning and the partitioning to $\mathrm{NO}$ from $\mathrm{NO}_{2}$ increases with altitude. Based upon the meteorological analysis from Fuelberg et al. [2007] employing $1.5^{\circ} \times 1.5^{\circ}$ grid boxes, we find that for the UT data being considered $(N=1188) 90 \%$ of the perturbed air masses in the $10-12 \mathrm{~km}$ range have been influenced by 


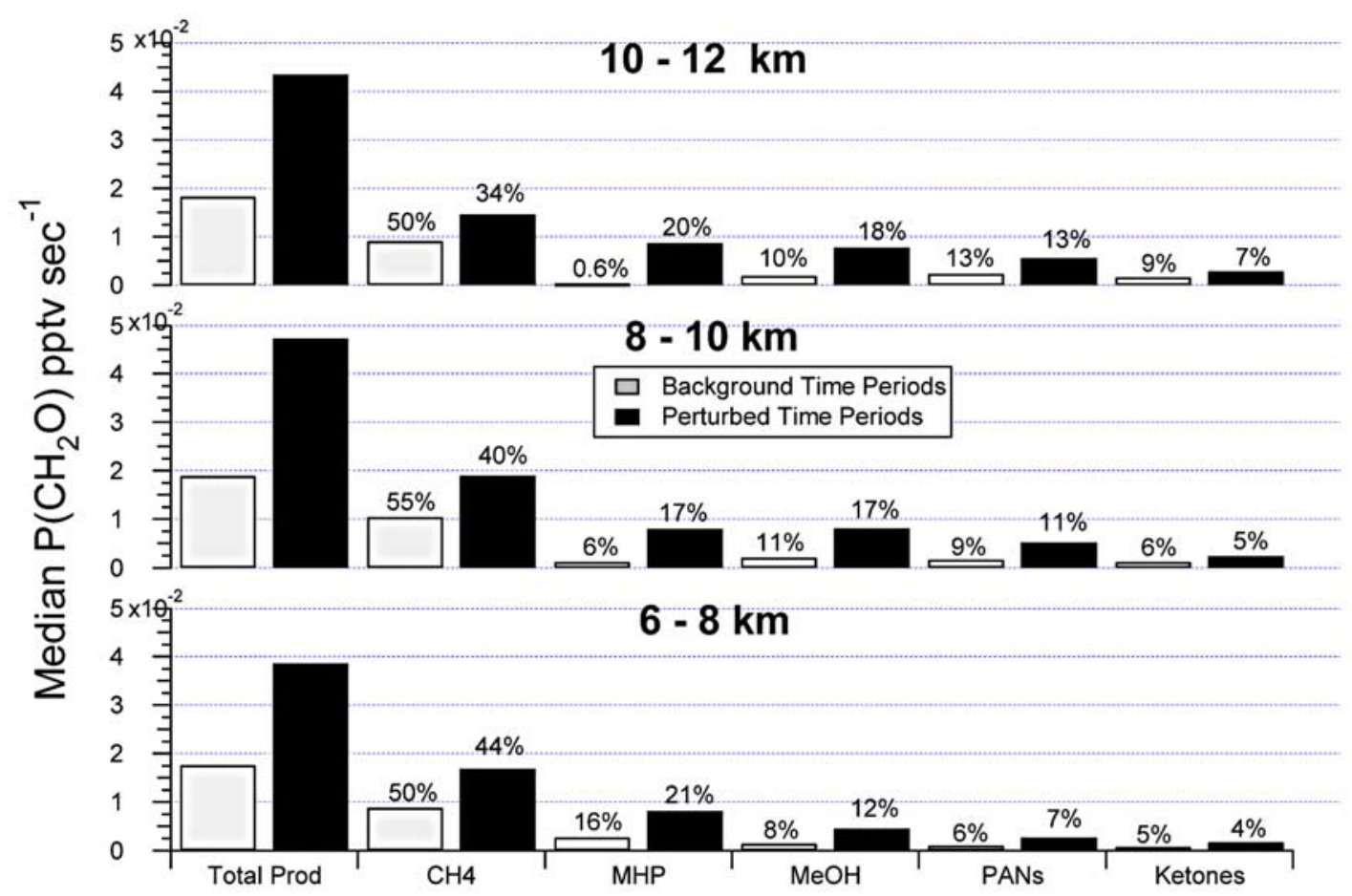

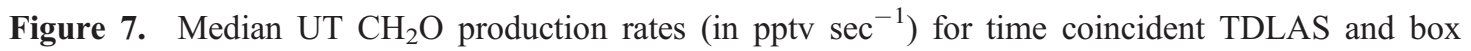
model results for background and perturbed time periods when measurements of MHP are used as model constraints. These results are from the box model for the major production terms only; $\mathrm{MHP}$ is $\mathrm{CH}_{3} \mathrm{OOH}$, $\mathrm{MeOH}$ is methanol, PANs represent production from PAN and $\mathrm{RCO}_{3}$ type compounds, and Ketones include acetone and other ketones. Total Prod is the total production rate. The numbers above each term represent the production percentage for that air mass type in the given altitude bin.

lightning within the past 24 hours (median influence within past 2 hours before sampling) and this compares to $50 \%$ for background conditions (median influence within past 13 hours before sampling). Furthermore, such influence decreases with decreasing altitude. For the 6- to 8- $\mathrm{km}$ range, $53 \%$ and $27 \%$ of the perturbed and background air masses, respectively, have been influenced by lightning within the past 24 hours. The above observations with respect to $\mathrm{OH}$ and $\mathrm{NO}_{x}$ also explains the fact that median ratios between perturbed and background production rates from methane are within a factor of 2 for all UT altitudes, whereas the methane mixing ratios are only negligibly changed between these two air mass types (background 1.774 ppmv, perturbed $1.791 \mathrm{ppmv}$ in the $10-12 \mathrm{~km}$ region).

[26] It is instructive to compare the $\mathrm{CH}_{2} \mathrm{O}$ production budgets of Figure 7 to those determined by Stickler et al. [2006] in the UT over central-western Europe and the northwestern Mediterranean region. During background and convectively influenced time periods between 6 and $7 \mathrm{~km}$, Stickler et al. [2006] determined production percentages from $\mathrm{CH}_{4}$ ranging between $26 \%$ to $40 \%$ and $29 \%$ to $44 \%$, respectively. Ranges are presented for each air mass type due to differing assumptions. These percentages only reflect the percentages from the reaction between $\mathrm{CH}_{3} \mathrm{O}_{2}$ and $\mathrm{NO}$ arising from $\mathrm{CH}_{4}$ decomposition. This background range is considerably lower than the present value of $50 \%$ for the $6-8 \mathrm{~km}$ altitude range, but the convectively influenced $\mathrm{CH}_{4}$ production contribution spans the $44 \%$ value determined here. For the $10-11 \mathrm{~km}$ range, Stickler et al. [2006] determined production percentages from $\mathrm{CH}_{4}$ of $35 \%$ to $53 \%$ and $31 \%$ to $47 \%$, respectively, for background and convectively influenced air, and this is in reasonable accord with present values of $50 \%$ and $34 \%$ for corresponding air mass types in the $10-12 \mathrm{~km}$ range. The next highest contribution in the Stickler study is methanol followed by MHP for both background and perturbed air masses. This order is reversed in most cases in the present study, but the production percentages for these two species are generally similar in both studies. The UT production contributions from other species such as acetaldehyde, PAN, and acetone in the Stickler study were all minor compared to $\mathrm{CH}_{4}$, methanol, and $\mathrm{MHP}$, and this is similar to the present study.

[27] The Stickler et al. [2006] study comes to the same conclusion as the present study regarding the importance of the transport of $\mathrm{CH}_{2} \mathrm{O}$ precursors to the UT and the enhanced photochemical activity from $\mathrm{NO}$ due to lightning. However, a comparison of the total $\mathrm{CH}_{2} \mathrm{O}$ production rates between the two studies indicates significantly enhanced photochemical activity at the highest altitudes over Europe compared to North America. For example, the Stickler et al. [2006] study $(10-11 \mathrm{~km})$ reports $\mathrm{CH}_{2} \mathrm{O}$ production rates of $3 \times 10^{5}$ and $1.2 \times 10^{6}$ molecules $\mathrm{cm}^{-3} \mathrm{~s}^{-1}$ for background and convective air, respectively, and this compares to significantly smaller median values of $1.5 \times 10^{5}$ and $3.4 \times$ $10^{5}$ molecules $\mathrm{cm}^{-3} \mathrm{~s}^{-1}$ for the $10-12 \mathrm{~km}$ range of the 

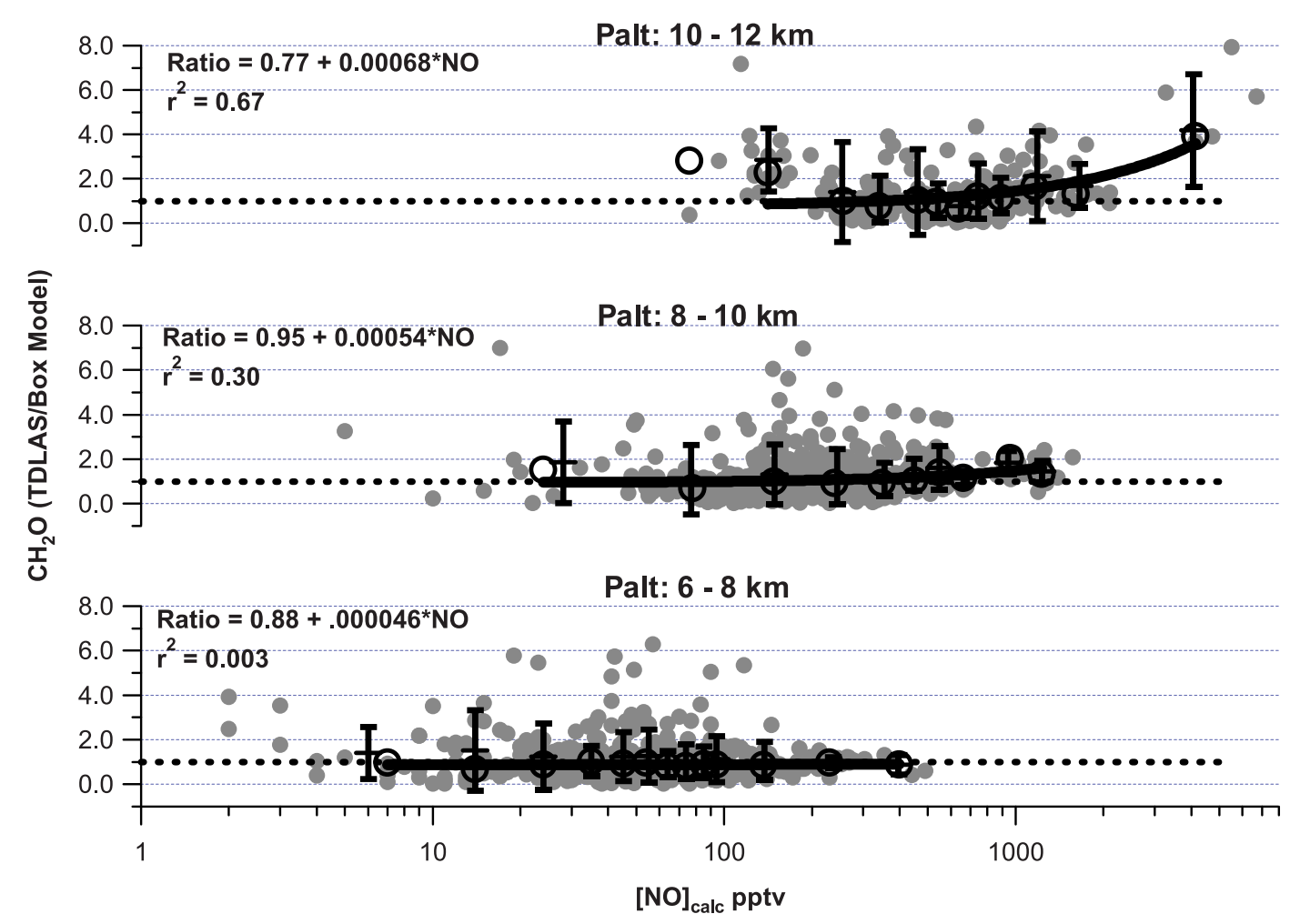

Figure 8. Binned $\mathrm{CH}_{2} \mathrm{O}$ measurement (TDLAS/Box model) ratio as a function of binned NO (from $\mathrm{NO}_{2}$ measurements and photostationary state calculations) for three pressure altitudes in the UT. Calculations were only performed for time coincident TDLAS and box model results where MHP was used in the model constraint. The open black circles are binned median ratios versus binned median NO, the horizontal lines are the binned averaged ratios versus binned averaged NO with 1 standard deviation limit, and the light gray points are the individual ratios. The solid dark lines are linear fits of the binned median values for each altitude bin, and the results of these fits are shown with each altitude bin along with the $r^{2}$ correlation coefficients. The first binned point in the $10-12 \mathrm{~km}$ range was not included in this fit since there were only 3 points in this bin. All the other bins have at least 7 points with the exception of the highest bin in the $6-8 \mathrm{~km}$ range $(N=4)$. The fits appear curved here when plotting a linear fit on a semilog axis. The NO bin widths are $6-8 \mathrm{~km}, 10$ pptv below 100 pptv and 100 or 200 pptv above this; $8-10 \mathrm{~km}, 50$ or $100 \mathrm{pptv}$ below $600 \mathrm{pptv}$ and $200 \mathrm{pptv}$ and greater above this; $10-12 \mathrm{~km}, 100 \mathrm{pptv}$ below $800 \mathrm{pptv}$ and greater than this above this level (the highest bin width extends from 2000 to 7000 pptv and contains 7 points, 5 of which yield ratios above 3.5).

present study. There are many potential reasons for this difference which need to be further investigated.

\section{6. $\mathrm{CH}_{2} \mathrm{O}$ Measurement-Model Ratios in the UT Versus NO and Relationship to $\mathrm{HO}_{2}$ Ratios}

[28] As noted throughout this paper, the production rate for $\mathrm{CH}_{2} \mathrm{O}$ is dramatically affected by $\mathrm{NO}$, with the largest measurement-model differences occurring at the highest NO mixing ratios. The modeling study by Wang and Prinn [2000] reveals a doubling in the $\mathrm{CH}_{2} \mathrm{O}$ production rate in the presence of lightning in the midtroposphere due to an enhancement in the reaction between $\mathrm{CH}_{3} \mathrm{O}_{2}$ and NO. To further investigate the correlation between $\mathrm{CH}_{2} \mathrm{O}$ and $\mathrm{NO}$ in this study, Figure 8 plots the dependence of the (TDLAS/ Box Model) ratio as a function of calculated NO for the 3 different altitude bins in the UT employing the same 1188 comparison points used throughout. Here we plot the binned median and average measurement/model ratios as a function of $\mathrm{NO}$ (median NO for the median ratio and average NO for the average ratio). Also shown are the individual ratio measurements.

[29] Linear fits of the measurement/model ratios (shown by the dark solid lines) are given with altitude bin along with the $r^{2}$ correlation coefficients. The first point in the $10-12 \mathrm{~km}$ bin was excluded from this fit due to the sparseness of the data $(N=3)$ and the resultant undue influence of a spurious comparison point residing in this bin; for this point (measurement/model ratio $=20.8$ ) there was only $5 \% \mathrm{CH}_{2} \mathrm{O}$ measurement coverage, see Fried et al. [2008]. By contrast, there was at least $40 \%$ measurement coverage and more typically $65 \%$ coverage for the 7 highest NO points in the $10-12 \mathrm{~km}$ bin. As can be seen by the linear fits, there is an increasing trend in the measurement/ model ratio with NO that becomes apparent in the $10-12 \mathrm{~km}$ range; here the highest NO mixing ratios (bin median = $4137 \mathrm{pptv}$, maximum individual value $=6713 \mathrm{pptv}$ ) were encountered. In the $6-8 \mathrm{~km}$ bin, the slope and correlation coefficient show no trend with NO. By contrast, the $10-$ $12 \mathrm{~km}$ bin yields an order of magnitude larger slope and a 


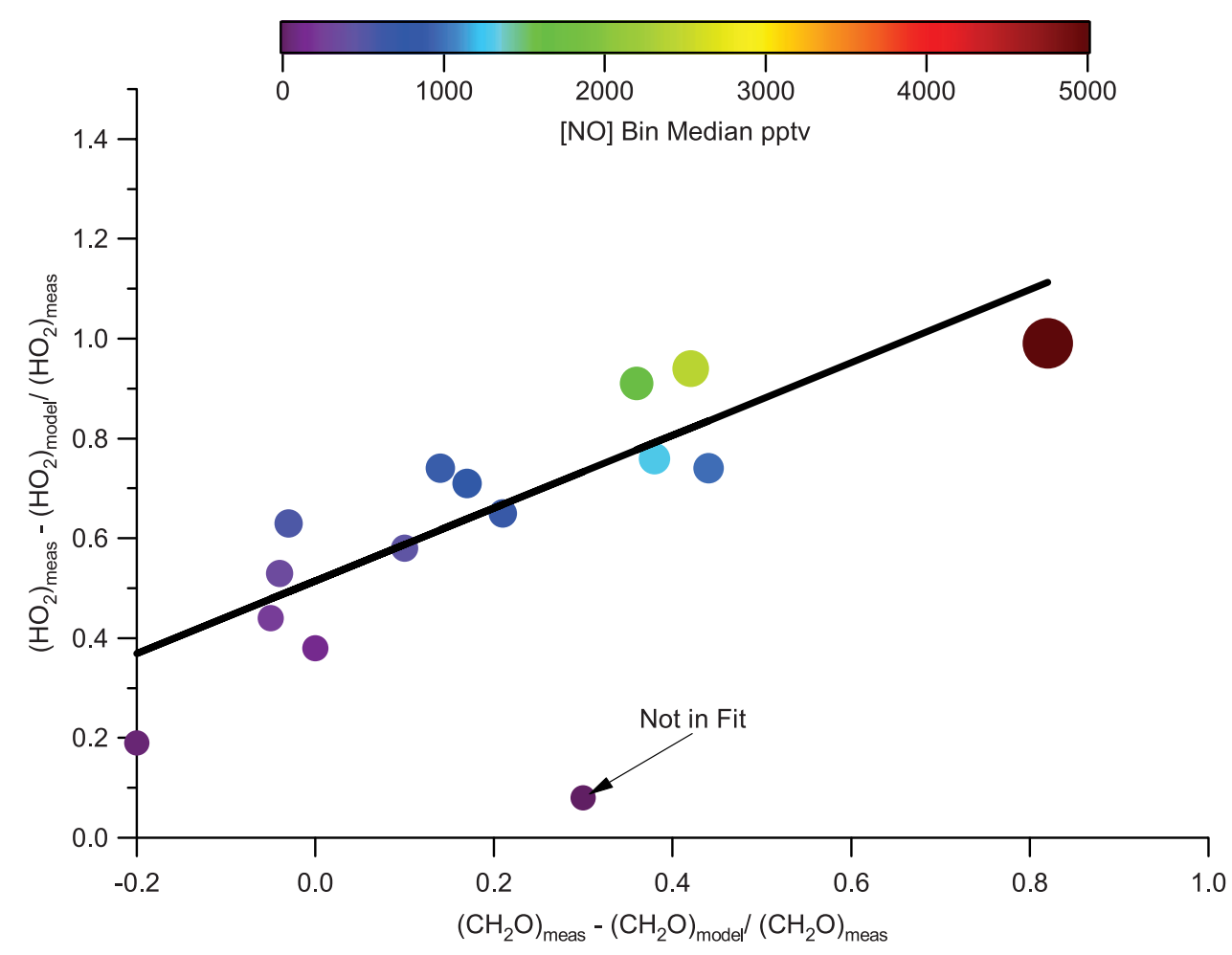

Figure 9. Median fractional difference (measurement-model/measurement) for $\mathrm{HO}_{2}$ versus that for $\mathrm{CH}_{2} \mathrm{O}$ in the $8-12 \mathrm{~km}$ altitude range binned by the median value of $\mathrm{NO}$ calculated. The bin size for most of the data shown here is 100 pptv. This plot shows data only when there were $\mathrm{CH}_{2} \mathrm{O}$ measurementmodel comparison points when the model was constrained by MHP measurements. The data are colored and sized by the binned NO median values. The solid line is a linear fit of 14 points (slope $=0.73 \pm 0.12$, intercept $=0.51 \pm 0.04, r^{2}=0.77$ ). The anomalously low point indicated and further discussed in the text was not included in this fit.

correlation coefficient (0.67), which reveals an NO-dependent discrepancy. The $8-10 \mathrm{~km}$ bin shows intermediate behavior.

[30] Such discrepancies in the UT imply one or a combination of the following: (1) reactions between $\mathrm{CH}_{3} \mathrm{O}_{2}$ and NO in the model that are too slow compared to reality; (2) additional reactions involving $\mathrm{NO}$ not in the box model that produce $\mathrm{CH}_{2} \mathrm{O}$; (3) additional unknown $\mathrm{CH}_{2} \mathrm{O}$ hydrocarbon precursors present during convection and high NO; (4) low modeled $\mathrm{OH}$ values compared to actual mixing ratios; (5) modeled $\mathrm{CH}_{2} \mathrm{O}$ sink terms that are too fast compared to reality; (6) heterogeneous formation of $\mathrm{CH}_{2} \mathrm{O}$ from methanol in clouds [Tabazadeh et al., 2004]; and/or (7) evaporation of $\mathrm{CH}_{2} \mathrm{O}$ from aerosols, cloud droplets, or cloud ice particles in our heated inlet. Each possibility will be discussed. It is important to first note, that depending upon the $\mathrm{CH}_{2} \mathrm{O}$ precursor type, enhanced $\mathrm{NO}$ may not in all cases yield elevated $\mathrm{CH}_{2} \mathrm{O}$ production. As shown in Figure 3, convection of methanol and MHP are not affected by NO for gas phase reactions, unless the back conversion of MHP to $\mathrm{CH}_{3} \mathrm{O}_{2}\left(\mathrm{CH}_{3} \mathrm{OOH}+\mathrm{OH} \rightarrow \mathrm{CH}_{3} \mathrm{O}_{2}+\mathrm{HO}_{2}\right)$ dominates the decomposition of MHP in producing $\mathrm{CH}_{2} \mathrm{O}$.

[31] Measurement-model comparisons of $\mathrm{HO}_{2}$ in the UT by Ren et al. [2008] during INTEX-NA show a very similar trend with $\mathrm{NO}$ above $8 \mathrm{~km}$ as our $\mathrm{CH}_{2} \mathrm{O}$ comparisons in Figure 8. Constraining the $\mathrm{HO}_{2}$ calculation using measured
$\mathrm{CH}_{2} \mathrm{O}$ values only reduces the $\mathrm{HO}_{2}$ measurement/model discrepancy with $\mathrm{NO}$ above $8 \mathrm{~km}$ slightly from a value of $\sim 3.8$ to 3.0 at the highest $\mathrm{NO}$ values. Reconciling the $\mathrm{HO}_{2}$ discrepancy by increasing $\mathrm{CH}_{2} \mathrm{O}$ photolysis rates has been discounted by Ren et al. [2008]; these researchers point out that it is quite unlikely that the photolysis frequencies are in error by the required factors of 4 to 6 . Such errors, moreover, would further exacerbate the $\mathrm{CH}_{2} \mathrm{O}$ discrepancy unless simultaneously accompanied by substantial increases in $\mathrm{CH}_{2} \mathrm{O}$ production rates. Although additional reactions between $\mathrm{OH}$ and methanol produce additional $\mathrm{HO}_{2}$ and $\mathrm{CH}_{2} \mathrm{O}$, this channel is $\mathrm{NO}$ independent.

[32] To examine the model deficit for both $\mathrm{CH}_{2} \mathrm{O}$ and $\mathrm{HO}_{2}$ as a function of $\mathrm{NO}$, we plot in Figure 9 the relationship between the median fractional difference (measurement-model/measurement) for $\mathrm{HO}_{2}$ versus $\mathrm{CH}_{2} \mathrm{O}$ for NO binned values in the $8-12 \mathrm{~km}$ range. For most of the data, we employed an NO bin size of 100 pptv. As can be seen by the linear fit (solid line), the discrepancy for $\mathrm{HO}_{2}$ is well correlated with that for $\mathrm{CH}_{2} \mathrm{O}$ when binned by $\mathrm{NO}$ $\left(r^{2}=0.77\right)$. It is interesting to note that the highest discrepancies for both $\mathrm{CH}_{2} \mathrm{O}$ and $\mathrm{HO}_{2}$ above 1000 pptv NO are also associated with the highest ultrafine condensation nuclei (UCN) values, aerosols with diameters as small as $3 \mathrm{~nm}$. High UCN number densities generally reflect new particle formation. In the outflow of clouds, UCN values are 
(a)

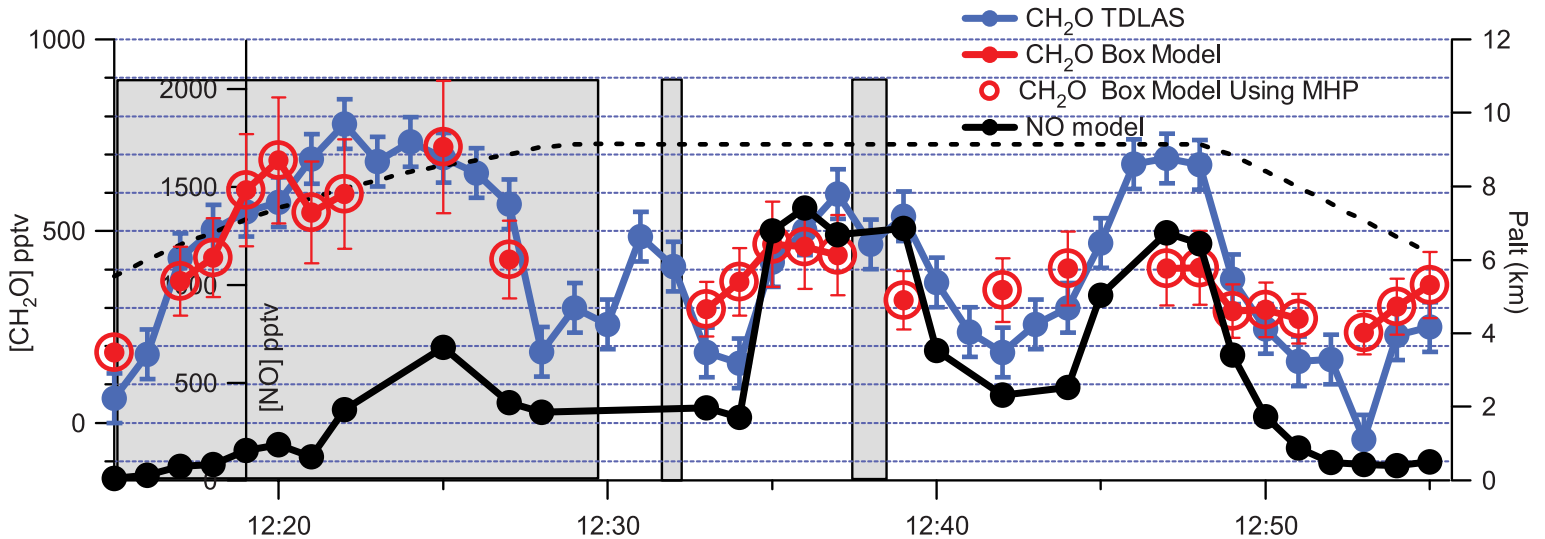

(b)

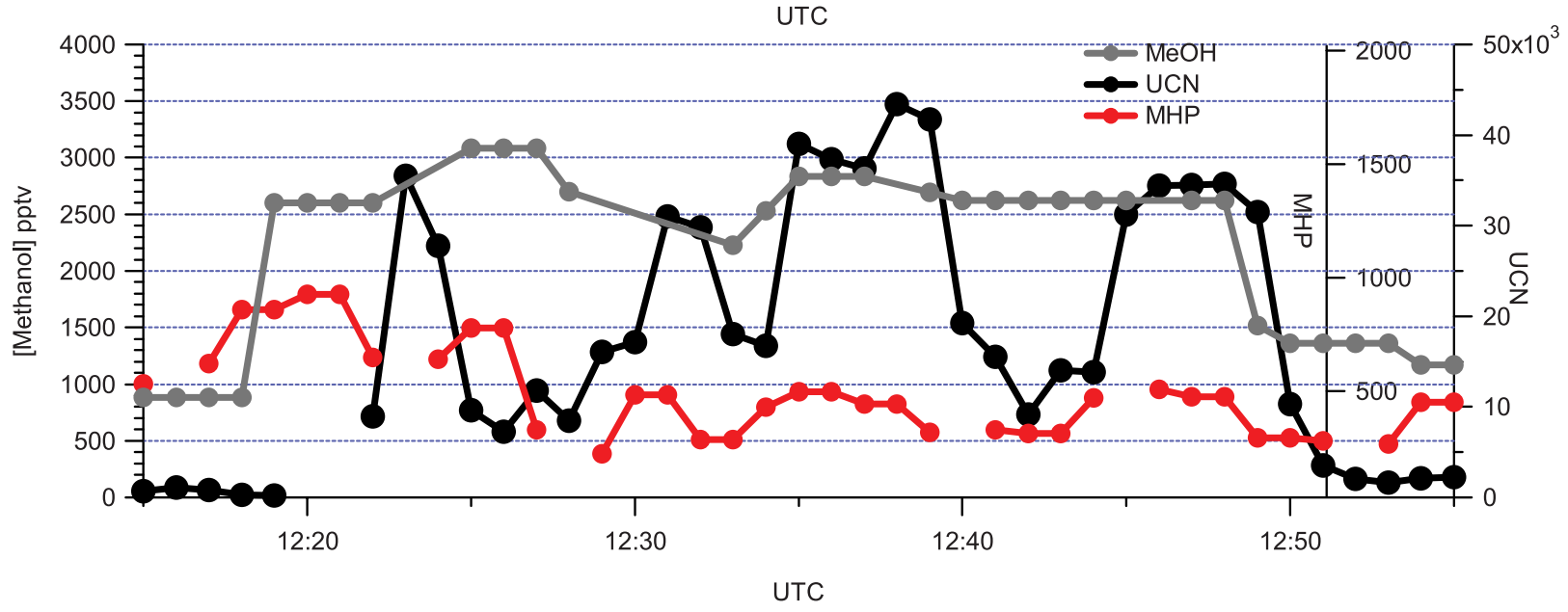

Figure 10. (a, b) Convective outflow event on 11 August 2004. The shaded regions in (a) indicate when the DC-8 was sampling in nonclear regions (clouds, haze, and intermediate haze). At 12:20 and 12:21 the DC- 8 was in clouds. The TDLAS and box model error bars are the random uncertainties at the $2 \sigma$ level and the dashed line in (a) indicates the pressure altitude using the right hand axis. The methanol $(\mathrm{MeOH})$ data are based on measurements from the NASA Ames PANAK system with data interpolated between measurement points. All comparisons in this case use MHP as a model constraint. The peak numbers in the text refer to the following time periods: peak 1, 12:20-12:26; peak 2, 12:35-12:39; peak 3, 12:46-12:48.

often elevated due to fresh sulfuric acid production from $\mathrm{SO}_{2}$ outflow, which reacts with enhanced $\mathrm{OH}$ caused by the elevated NO. Therefore the apparent correlation in the discrepancies with UCN may be coincidental since the highest UCN values are also associated with the highest NO values from the above mechanism. In fact, it is difficult to find cases where NO levels are high and the UCN are less than their median UT values. Even at NO mixing ratios less than $1000 \mathrm{pptv}, \mathrm{UCN}$ and $\mathrm{NO}$ are still correlated, making it difficult to assign the prime contributor of the $\mathrm{CH}_{2} \mathrm{O}$ and $\mathrm{HO}_{2}$ discrepancies. However, a plot of the $\mathrm{CH}_{2} \mathrm{O}$ discrepancy versus NO and colored by UCN (not shown) suggests that NO appears to be the more important factor. Section 8 will further explore one specific example where NO and UCN number densities are elevated.

\section{Case Studies of UT Convection}

[33] While the $\mathrm{CH}_{2} \mathrm{O}$ measurements and box model relationships discussed give us an overview of UT $\mathrm{CH}_{2} \mathrm{O}$ convective perturbations, this analysis does little to show our understanding and limitations during individual perturbation events. In this section we examine two different convective cases in the UT: one involving convection of a mixed anthropogenic and biogenic plume and a second involving convection of well aged air with recent large $\mathrm{NO}$ inputs. Both cases exemplify the $\mathrm{CH}_{2} \mathrm{O}$ and $\mathrm{HO}_{2}$ discrepancies with $\mathrm{NO}$ previously discussed.

[34] Figure 10 displays the first case over the MaineNew Brunswick border at $9.1 \mathrm{~km}$ on August 11, 2004 and reveals good $\mathrm{CH}_{2} \mathrm{O}$ TDLAS box model agreement for two of the three large excursions. The shaded regions indicate sampling during nonclear periods, which for times around 12:20 represent sampling in clouds. Based upon elevated $\mathrm{CO}, \mathrm{SO}_{2}, \mathrm{UCN}$, and MHP, the entire flight leg indicates convection of anthropogenic pollutants but no fire influence (using the 4 fire indicators). However, an observed depression in $\mathrm{CO}_{2}$ also suggests some biogenic origin to the convection from photosynthetic uptake. Since this process occurs during daylight hours, and the sampling time starts at 

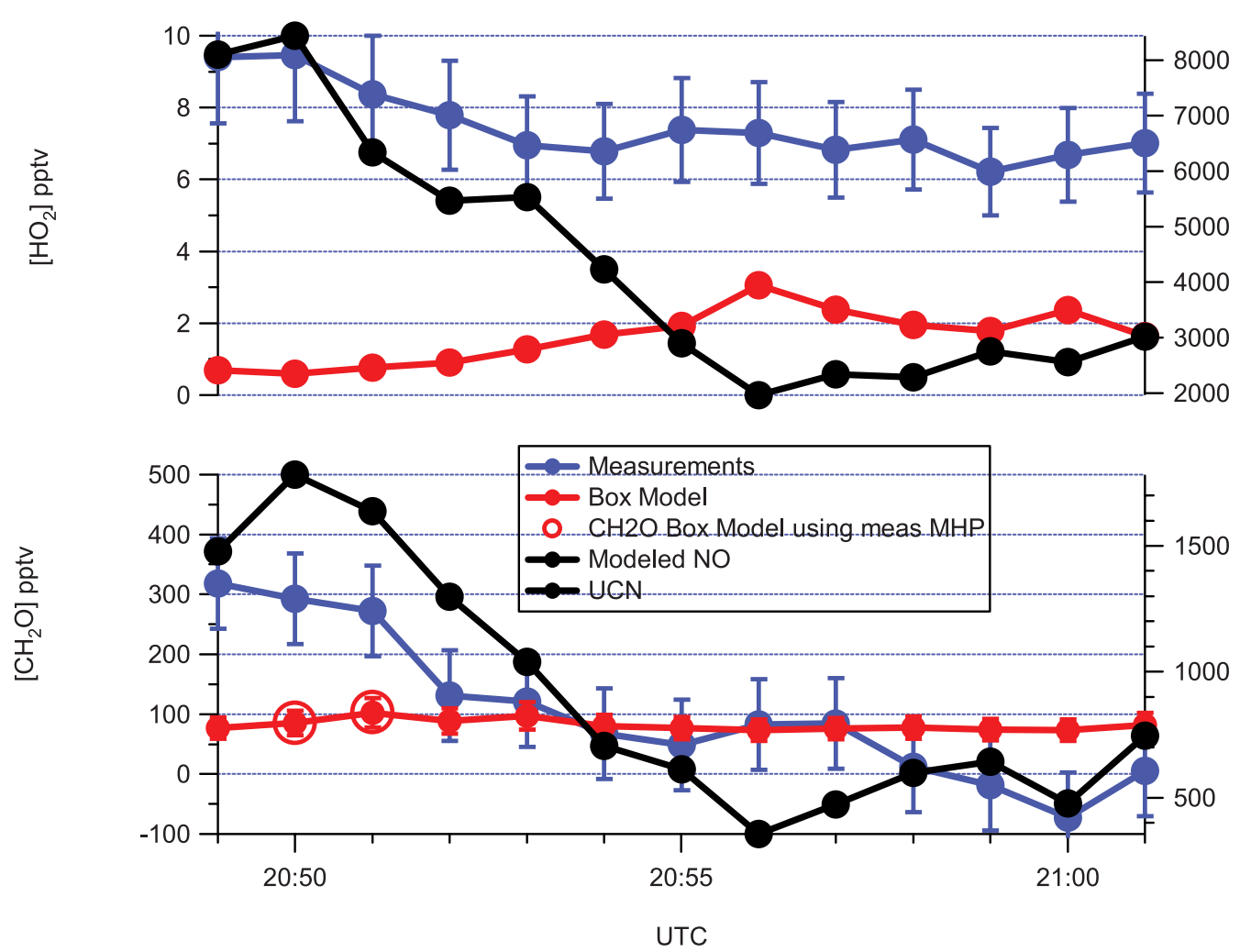

Figure 11. $\mathrm{CH}_{2} \mathrm{O}$ and $\mathrm{HO}_{2}$ measurements and box model values for a flight leg on 8 July 2004 at $10.7 \mathrm{~km}$ over South Carolina. The calculated NO mixing ratios and measured UCN (right axes) are also shown. The error bars on the measurement and model results are the random uncertainties at the $2 \sigma$ level.

7:15 AM (local time), the contact with the biosphere must have originated at least 12 hours prior to sampling. Analysis using FLEXPART [Stohl et al., 1998] indicates contact with the biosphere several days prior to sampling. Based upon the meteorological analysis by Fuelberg et al. [2007] and the $\mathrm{NO}_{x} / \mathrm{HNO}_{3}$ ratios by Bertram et al. [2007], the convection and lightning influences were very recent in origin $(0$ to 10 hours for both). The ratio between heated to unheated condensation nuclei number densities ( 0.1 in all cases) indicated a well-aged nonrefractory plume. This ratio was measured with the same condensation nuclei instrument by heating the inlet to $300{ }^{\circ} \mathrm{C}$ relative to an unheated inlet. High ratios indicate a large number density of refractory species, which are typically dominated by soot, fly ash and generally indicative of pollution. The benzene to toluene ratios also indicated a well aged plume of 22 to 35 hours old [Colomb et al., 2006]. Collectively, all the indicators above indicate a well aged mixed biogenic/anthropogenic plume with recent convection and lightning influences.

[35] Thus one would expect elevated UT measurements and box model results for $\mathrm{CH}_{2} \mathrm{O}$, and given the age of the plume, these two results should agree. Figure 10 panel (a) shows the resulting comparison between $\mathrm{CH}_{2} \mathrm{O}$ measurements and box model results with random uncertainty limits (at the $2 \sigma$ level) for both. The modeled NO profile is also shown. The $\mathrm{CH}_{2} \mathrm{O}$ measurements and model results are in reasonable agreement (with a few exceptions) for the first two peaks but the model underestimates the observations by $286 \mathrm{pptv}$ for the $3 \mathrm{rd}$ peak $\left(\mathrm{R}\left(\mathrm{CH}_{2} \mathrm{O}\right)=\right.$ measurement $/$ model
= 1.7). Based upon the model production rates, MHP dominates $\mathrm{CH}_{2} \mathrm{O}$ production throughout Figure 10 (43 to $47 \%$ of the total $\mathrm{CH}_{2} \mathrm{O}$ production). This explains the reduced $\mathrm{NO}$ effect on $\mathrm{CH}_{2} \mathrm{O}$ for the 2nd peak $\left(\mathrm{R}\left(\mathrm{CH}_{2} \mathrm{O}\right)\right.$ $=1.1$ ), even in the presence of $\mathrm{NO}=1393$ pptv. However, the last two points of the 2nd peak (at 12:37 and 12:39) and the two points during the $3 \mathrm{rd}$ peak $(12: 47$ and $12: 48)$ show both $\mathrm{CH}_{2} \mathrm{O}$ and $\mathrm{HO}_{2}$ discrepancies $\left(\mathrm{R}\left(\mathrm{CH}_{2} \mathrm{O}\right)=1.3\right.$ to 1.7 , $\mathrm{R}\left(\mathrm{HO}_{2}\right)=2.8$ to 3.9) for NO levels similar to the start of the 2nd peak. This contrasting behavior with NO and MHP perhaps suggests a different air mass with unknown precursors for some of the peaks. It is interesting to note that the relative enhancements in UCN (peak - local background value/local background value) are very similar to those for measured $\mathrm{CH}_{2} \mathrm{O}$ for all three peaks, reinforcing our discussion above that $\mathrm{CH}_{2} \mathrm{O}$ enhancements may be related to similar cloud outflow processes as those responsible for the UCN formation. However, as the NO profiles are also similar in shape, these two effects cannot be separated. Clearly the varying behavior of Figure 10 points to gaps in our understanding.

[36] Figure 11 shows a second case study. Measurements here were acquired at $10.7 \mathrm{~km}$ over South Carolina on 8 July 2004. This example shows convection of well aged air with recent large NO inputs from lightning. Back trajectories indicated the air passed over the south eastern United States but remained at altitude between 7 and $10.7 \mathrm{~km}$ over the past two days. As can be seen, UCN and NO were both significantly elevated at the start of this leg. Both peaked at 
20:50 where the $\mathrm{CH}_{2} \mathrm{O}$ and $\mathrm{HO}_{2}$ displayed their greatest discrepancies $\left(\mathrm{R}\left(\mathrm{CH}_{2} \mathrm{O}\right)=3.4, \mathrm{R}\left(\mathrm{HO}_{2}\right)=16.0\right)$. Here MHP values were low enough $($ median $=44)$ that $\mathrm{MHP}$ exerted a small influence on $\mathrm{CH}_{2} \mathrm{O}$ production and it made no difference whether or not measured or modeled MHP was employed in the $\mathrm{CH}_{2} \mathrm{O}$ calculation. Thus one would expect an NO effect that is not moderated by MHP, as is the case. As the $\mathrm{NO}$ dropped, the $\mathrm{CH}_{2} \mathrm{O}$ measurements came into agreement with the model, but the $\mathrm{R}\left(\mathrm{HO}_{2}\right)$ values were still significantly greater than 1 , even for $\mathrm{NO}$ values $<1000$ pptv. In contrast to the $\mathrm{CH}_{2} \mathrm{O}$ profile, where the measurements declined by over 200 pptv while model values were relatively constant, the $\mathrm{HO}_{2}$ measurement declined by $\sim 2.6$ pptv while the model increased by approximately this value. At the peak (20:50), many organic species were near their overall 10-12 km median values, with a few exceptions (propane and the butanes were 2 to 3 times their median values). Anthropogenic combustion tracers like $\mathrm{CO}$, ethyne, and $\mathrm{SO}_{2}$ were all less than their $10-12 \mathrm{~km}$ median values. At times around 20:50, the Fuelberg analysis indicated a time since convection of $\sim 3$ hours but lightning influence within 1 hour of sampling. Based on equation (2) $\left(\mathrm{CH}_{2} \mathrm{O}\right.$ lifetime $=1.5$ hours $)$ direct convection of $\mathrm{CH}_{2} \mathrm{O}$ should not be important here.

\section{Possible Causes of the $\mathrm{UT} \mathrm{CH}_{2} \mathrm{O}$ and $\mathrm{HO}_{2}$ Discrepancies}

[37] The two convective cases in the UT just examined show time periods where measurements of $\mathrm{CH}_{2} \mathrm{O}$ are in agreement with model calculations and time periods where both $\mathrm{CH}_{2} \mathrm{O}$ and $\mathrm{HO}_{2}$ observations are significantly higher than box model calculations when NO is elevated. In this section we examine the 7 potential causes for this observation raised in section 6 .

[38] During both case studies just discussed for the constant altitude portions of the measurement-model comparisons, changes in ambient temperatures and pressures were all less than $0.5 \%(0.8 \mathrm{~K}$ and $0.3 \mathrm{mb})$. Thus the variability of the measurement-model comparison during these flight legs implies that temperature and pressure related rate constant and photolysis frequency errors as well as branching ratio errors (potential cause \#5) can be ruled out. Errors in any of these parameters would not yield measurement-model agreement during parts of the flight legs and disagreement during other parts. A full description of the box model and the modeling approach are included in the companion paper by Fried et al. [2008]. Photolysis rates are based on observed values, so enhancements and reductions in the radiation field due to cloud impacts is implicitly accounted for in the modeling calculations. Likewise, this logic also rules out errors in the rate constant for $\mathrm{CH}_{3} \mathrm{O}_{2}+$ NO (potential cause \#1) as well as additional reactions that produce $\mathrm{CH}_{2} \mathrm{O}$ and $\mathrm{HO}_{2}$ in the atmosphere involving $\mathrm{NO}$ which are not currently represented in box models (potential cause \#2), unless heterogeneous production on aerosols, which is time coincident with the elevated NO becomes important. The 4th potential cause, significantly lower modeled $\mathrm{OH}$ mixing ratios than those measured can be ruled out; in the 1st case study modeled $\mathrm{OH}$ values were higher than measured. In the 2nd case study of Figure 11 the $\mathrm{R}\left(\mathrm{CH}_{2} \mathrm{O}\right)=3.5$ value at 20:50 using modeled $\mathrm{OH}$ only reduces to $\sim 2.1$ when employing measured $\mathrm{OH}$. This leaves us with three possibilities for the observed discrepancies: unmeasured hydrocarbon precursors (potential cause \#3), heterogeneous formation of $\mathrm{CH}_{2} \mathrm{O}$ on aerosols and/or in clouds; and/or evaporation of $\mathrm{CH}_{2} \mathrm{O}$ from aerosols, cloud droplets, and/or ice particles in our inlet (potential cause \#7). In section 6 we discussed the possibility that in addition to elevated $\mathrm{NO}$, elevated ultrafine condensation nuclei may also play some role in causing the observed $\mathrm{CH}_{2} \mathrm{O}$ and $\mathrm{HO}_{2}$ measurement-model discrepancies in the UT. However, both the surface area and volume of UCNs are orders of magnitude too low for heterogeneous reactions to be important here. Such reactions therefore would require surface areas such as those found in clouds. Heterogeneous processing of methanol to form $\mathrm{CH}_{2} \mathrm{O}$ in certain clouds (potential cause \#6) is one such possibility discussed by Tabazadeh et al. [2004]. These researchers presented evidence based upon Fourier Transform IR measurements to support the importance of this mechanism in clouds that have encountered biomass burning plumes. One possible mechanism postulated involved cloud uptake of $\mathrm{NO}_{2}$ and the formation of $\mathrm{HO}_{2}$, both of which are consistent with the observations of this study. These authors further raised the possibility of similar processes occurring on more pristine clouds (no biomass burning influence), as would be needed to explain the present observations; as discussed previously, biomass burning influence was not evident in the present discrepancies.

[39] Of the two case studies presented, the total cloud surface area density was only appreciable for the 1 st case study (Figure 10) around 12:20. Here the DC-8 was sampling in clouds with a total surface area density, $\mathrm{S}$, of $0.0016 \mathrm{~cm}^{2} \mathrm{~cm}^{-3}$ for cloud particles in the $0.3-$ to $1550-\mu \mathrm{m}$ size range. Assuming that the cloud surface area size distribution here was equivalent to that in Tabazadeh et al. [2004] and that the Tabazadeh heterogeneous normalized rate constant in smoke/cloud plumes for reactions involving $\mathrm{NO}_{2}\left(\mathrm{k}_{\text {het }}=4.3 \times 10^{-13} \mathrm{~cm}^{3} \mathrm{~cm} \mathrm{~s}^{-1}\right)$ was also appropriate for the pristine clouds of the present study, we estimate the magnitude of heterogeneous production of $\mathrm{CH}_{2} \mathrm{O}$ from Tabazadeh et al. [2004]:

$$
\left[\mathrm{CH}_{2} \mathrm{O}\right]_{\text {het }}=[\text { Processing Time }]\left[\mathrm{k}_{\text {het }}\right][\mathrm{S}]\left[\mathrm{NO}_{2}\right]\left[\mathrm{CH}_{3} \mathrm{OH}\right]
$$

[40] The Fuelberg et al. [2007] convective analysis indicated that the air sampled at 12:20 was exposed to fresh convection for the past 21 hours, and IR satellite imagery coupled with back trajectories indicated that this air was in clouds for at least 8 hours prior to sampling. Assuming a surface area density of $0.0016 \mathrm{~cm}^{2} \mathrm{~cm}^{-3}$ for the entire cloud exposure, a processing time of 8 hours, $\mathrm{NO}_{2}$ and methanol mixing ratios of 315 pptv and 2741 pptv, respectively (measured at 12:20, an air number density $\mathrm{M}=1.1 \times$ $10^{19}$ molecules $\mathrm{cm}^{-3}$ ), we calculate a $\mathrm{CH}_{2} \mathrm{O}$ mixing ratio of

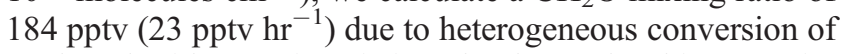
methanol with $\mathrm{NO}_{2}$ in pristine clouds. Under this scenario, we should have observed a $\mathrm{CH}_{2} \mathrm{O}$ measurement-model discrepancy of +184 pptv at 12:20, since the box model does not include this process. The actual measurementmodel discrepancy at 12:20 was -110 pptv and averaged $51 \pm 106 \mathrm{pptv}$ for the entire nonclear period around 12:20. The largest discrepancies observed in Figure 10 occurred 
at 12:47 and 12:48 (+277 pptv), 6 hours transport time after the cloud exposure at 12:20. As this is $\sim 4 \mathrm{CH}_{2} \mathrm{O}$ lifetimes, any heterogeneous cloud processing should have recovered by the time of sampling at 12:47 and 12:48. Given these facts, the heterogeneous conversion of methanol on pristine clouds to form $\mathrm{CH}_{2} \mathrm{O}$ in the presence of elevated $\mathrm{NO}_{x}$ in the UT is highly unlikely here.

[41] Considering the 7 highest NO points in the $10-12 \mathrm{~km}$ bin, we can also discount inlet evaporation of condensed phase $\mathrm{CH}_{2} \mathrm{O}$ (potential cause \#7) based upon a number of factors. Sampling for all 7 events occurred in clear air with low particle number densities and surface area densities and near zero liquid water contents (LWC). Based upon convection of boundary layer (BL) median $\mathrm{CH}_{2} \mathrm{O}$ values of 2065 pptv to the $10-12 \mathrm{~km}$ range, we estimate a required LWC of at least $0.025 \mathrm{~g} \mathrm{~m}^{-3}$ to yield the observed $\mathrm{CH}_{2} \mathrm{O}$ values (median $=201$ pptv) for the 7 events under consideration assuming that Henry's Law equilibrium is established in the BL and maintained at this value throughout the convection to the UT, whereupon the $\mathrm{CH}_{2} \mathrm{O}$ laden droplets totally evaporate in our heated inlet. During INTEX-NA the droplet mean diameter for this LWC typically ranged between 4 and $7 \mu \mathrm{m}$ in the $10-12 \mathrm{~km}$ range. As our rearfacing inlet should exclude particles larger than $\sim 1 \mu \mathrm{m}$ and more likely larger than $0.5 \mu \mathrm{m}$, it is unlikely that evaporation of liquid water droplets in our inlet should cause the observed discrepancy. In the case of ice formation, the retention of soluble gases like $\mathrm{CH}_{2} \mathrm{O}$ in the frozen particle (estimated at $\sim 50 \%$, Barth et al. [2007]) should make this issue even less likely. However, this analysis does suggest that evaporation of BL-transported $\mathrm{CH}_{2} \mathrm{O}$ from droplets/ice particles into the atmosphere in the UT may be an important atmospheric process not represented in current box models. Such processes, however, cannot explain the observed NO dependence for the 7 points in question.

[42] The final possibility for the observed NO discrepancies involves gas-phase reactions of unmeasured hydrocarbons, which most likely involve reactions of $\mathrm{RO}_{2}$ radicals with NO. Steady state estimates, carried out to assess the magnitude of such hydrocarbons, revealed that a relatively long-lived hydrocarbon with the same reactivity as propane $\left(\mathrm{k}_{\mathrm{OH}}=9.3 \times 10^{-13}\right)$ would need to be present at mixing ratios of approximately 2 ppbv. Faster reacting alkenes with the same reactivity as ethene and isoprene $\left(\mathrm{k}_{\mathrm{OH}}=6.6 \times 10^{-12}\right.$ and $\left.9.7 \times 10^{-11}\right)$ would need to be present at much lower mixing ratios below 250 pptv to yield the observed discrepancies. A large number of undetected slower reacting hydrocarbons at very low mixing ratios could also explain the observed discrepancies.

\section{Summary and Conclusions}

[43] Measurements of $\mathrm{CH}_{2} \mathrm{O}$ from a tunable diode laser absorption spectrometer (TDLAS) were acquired onboard the NASA DC-8 during the summer 2004 INTEX-NA campaign and employed to further test our understanding of hydrocarbon oxidation chemistry and convective transport in the upper troposphere $(6-12 \mathrm{~km})$ over continental North America and the North Atlantic Ocean. Various tracers were used to arrive at a set of 81 background air mass time periods in the UT, and this procedure resulted in a background $\mathrm{CH}_{2} \mathrm{O}$ cutoff limit of 165 pptv. Approximately
$40 \%$ of the collective UT $\mathrm{CH}_{2} \mathrm{O}$ observations and/or model results of the present study in the UT exceed this limit. Box model results indicated that in general $\mathrm{CH}_{2} \mathrm{O}$ production from $\mathrm{CH}_{4}$ was found to be the dominant source term in the UT, even in perturbed air masses. This was followed by production from $\mathrm{MHP}\left(\mathrm{CH}_{3} \mathrm{OOH}\right)$, methanol, PAN type compounds, and ketones, in descending order of their contribution. However, a number of convection cases were also identified where MHP and/or methanol played the dominant role in producing $\mathrm{UT} \mathrm{CH}_{2} \mathrm{O}$.

[44] Two different approaches indicated that at least $70 \%$ to $73 \%$ of the perturbed $\mathrm{CH}_{2} \mathrm{O}$ observations (values $>165 \mathrm{pptv}$ ) in the UT by TDLAS were caused by enhanced production from $\mathrm{CH}_{2} \mathrm{O}$ precursors, including enhancements from lightning-produced NO. A time-dependent box model indicates that such processes could affect UT radical and $\mathrm{O}_{3}$ production for as long as one or more weeks. For the remaining $27 \%$ to $30 \%$ of the time our perturbed UT observations can be ascribed to convection of $\mathrm{CH}_{2} \mathrm{O}$ precursors with or without direct $\mathrm{CH}_{2} \mathrm{O}$ convection. At present there is no way to separate these two effects, and thus $\mathrm{CH}_{2} \mathrm{O}$ precursors may be playing an even larger role in the UT.

[45] The median measurement/model ratio in the UT was 0.9 ( 0.5 to 1.5 at the $25 \%$ and $75 \%$ levels, respectively) when measurements of MHP were available to constrain the model $(N=1188)$. However, individual ratios exhibited a great deal of scatter. In the UT, $56 \%$ of the measurementmodel comparisons were within the combined random uncertainties and $62 \%$ were within the combined systematic uncertainty limits. A further comparison revealed that both measured and modeled $\mathrm{CH}_{2} \mathrm{O}$ were both significantly elevated in the UT when sampling in nonclear conditions due to convection of pollution. This increase was more than a factor of 2 in the $10-12 \mathrm{~km}$ range compared to clear conditions. Nevertheless, the median point-by-point measurement/model ratios were still in agreement during these conditions, indicating that the box model faithfully captures the observations during most of the convective perturbations throughout the UT and that $\mathrm{CH}_{2} \mathrm{O}$ is not permanently removed from the gas phase during most cloud encounters here.

[46] The $\mathrm{CH}_{2} \mathrm{O}$ UT measurement-model agreement was also studied as a function of NO. In the $10-12 \mathrm{~km}$ range there was a significant trend in this discrepancy, which was highly correlated with $\mathrm{HO}_{2}$ discrepancy. A detailed analysis of various possibilities points to unmeasured hydrocarbon precursors as the most likely source. It is clear that more systematic studies of $\mathrm{CH}_{2} \mathrm{O}$ and $\mathrm{HO}_{x}$ measurement-model relationships in the UT are needed as a function of $\mathrm{NO}$, particularly in and around clouds, and in the presence of high UCN number densities and high methanol mixing ratios. Systematic measurements are also needed where the cloud hydrometer types are well-characterized. Studying the behavior of $\mathrm{CH}_{2} \mathrm{O}$ during freezing nucleation processes, for example, would be of particular interest. Such a process would act as an efficient mechanism in transporting boundary layer $\mathrm{CH}_{2} \mathrm{O}$ to the UT. Based on the results of this study, it is clear that understanding radical chemistry in the UT requires reconciling $\mathrm{CH}_{2} \mathrm{O}$ measurement-model discrepancies in addition to those for $\mathrm{HO}_{2}$. This is particularly true since enhanced photochemical production of $\mathrm{CH}_{2} \mathrm{O}$ in the UT in the presence of convection and lightning was shown 
to be prevalent over a large fraction of our observations over North America and the North Atlantic Ocean.

[47] Acknowledgments. The National Center for Atmospheric Research is operated by the University Corporation for Atmospheric Research under the sponsorship of the National Science Foundation. This research was supported by funds from the National Aeronautics and Space Administration's Global Tropospheric Experiment. The authors specifically wish to acknowledge the NASA DC-8 staff and crew for all their valuable support and assistance and Mary Barth, Chris Cantrell, and John Orlando at NCAR for valuable discussions. The GEOS-Chem model is managed by the Atmospheric Chemistry Modeling group at Harvard University with support from the NASA Atmospheric Chemistry Modeling and Analysis Program.

\section{References}

Arakawa, A., and W. H. Schubert (1974), Interaction of a cumulus ensemble with the large-scale environment, part I, J. Atmos. Sci., 31, 674-704. Barth, M. C., S.-W. Kim, W. C. Skamarock, A. L. Stuart, K. E. Pickering, and L. E. Ott (2007), Simulations of the redistribution of formaldehyde, formic acid, and peroxides in the 10 July 1996 STERAO deep convection storm, J. Geophys. Res., 112, D13310, doi:10.1029/2006JD008046.

Bertram, T. H., et al. (2007), Direct measurements of the convective recycling of the upper troposphere, Science, 315(5813), 816-820.

Brune, W. H., et al. (1998), Airborne in-Situ OH and $\mathrm{HO}_{2}$ observations in the cloud-free troposphere and lower stratosphere during SUCCESS, Geophys. Res. Lett., 25(10), 1701-1704.

Cohan, D., S. M. G. Schultz, D. J. Jacob, B. G. Heikes, and D. R. Blake (1999), Convective injection and photochemical decay of peroxides in the tropical upper troposphere: Methyl iodide as a tracer of marine convection, J. Geophys. Res., 104(D5), 5717-5724.

Colomb, A., et al. (2006), Airborne measurements of trace organic species in the upper troposphere over Europe: The impact of deep convection, Environ. Chem., 3, 244-259, doi:10.1071/EN06020.

Crawford, J. H., et al. (1999), Assessment of upper tropospheric $\mathrm{HO}_{x}$ sources over the tropical Pacific based on NASA GTE/PEM data: Net effect on $\mathrm{HO}_{x}$ and other photochemical parameters, J. Geophys. Res., 104(D13), 16,255-16,273.

Dasgupta, P. K., J. Li, G. Zhang, W. T. Luke, W. A. McClenny, J. Stutz, and A. Fried (2005), Summertime ambient formaldehyde in five U.S. metropolitan areas: Nashville, Atlanta, Houston, Philadelphia, and Tampa, Environ. Sci. Technol., 39, 4767-4783.

Faloona, I., et al. (2000), Observations of $\mathrm{HO}_{x}$ and its relationship with $\mathrm{NO}_{x}$ in the upper troposphere during SONEX, J. Geophys. Res., 105(D3), $3771-3783$

Fried, A., Y.-N. Lee, G. Frost, B. Wert, B. Henry, J. R. Drummond, G. Hubler, and T. Jobson (2002), Airborne $\mathrm{CH}_{2} \mathrm{O}$ measurements over the North Atlantic during the 1997 NARE campaign: Instrument comparisons and distributions, J. Geophys. Res., 107(D4), 4039, doi:10.1029/2000JD000260.

Fried, A., et al. (2008), Formaldehyde over North America and the North Atlantic during the summer 2004 INTEX Campaign: Methods, observed distributions, and measurement box model comparisons, J. Geophys. Res., 113, D10302, doi:10.1029/2007JD009185.

Fuelberg, H. E., R. O. Loring Jr., M. V. Watson, M. C. Sinha, K. E. Pickering, A. M. Thompson, G. W. Sachse, D. R. Blake, and M. R. Schoeberl (1996), TRACE-A trajectory intercomparison: 2. Isentropic and kinematic methods, J. Geophys. Res., 101(D19), 23,927-23,939.

Fuelberg, H. E., M. J. Porter, C. M. Kiley, and D. Morse (2007), Meteorological conditions and anomalies during the Intercontinental Chemical Transport Experiment-North America, J. Geophys. Res., 112, D12S06, doi:10.1029/2006JD007734.

Global Climate and Weather Modeling Branch (2003), The GFS Atmospheric Model, NOAA/NWS/NCEP Office Note 442, 14 pp. (Available online at http://www.emc.ncep.noaa.gov/officenotes/newernotes/ on442.pdf.)

Jaeglé, L., et al. (1997), Observed $\mathrm{OH}$ and $\mathrm{HO}_{2}$ in the upper troposphere suggest a major source from convective injection of peroxides, Geophys. Res. Lett., 24(24), 3181-3184.

Jaeglé, L., D. J. Jacob, W. H. Brune, D. Tan, I. C. Faloona, A. J. Weinheimer, B. A. Ridley, T. L. Campos, and G. W. Sachse (1998a), Sources of HO Hand and production of ozone in the upper troposphere over the United States, Geophys. Res. Lett., 25(10), 1709-1712.

Jaeglé, L., et al. (1998b), Sources and chemistry of $\mathrm{NO}_{x}$ in the upper troposphere over the United States, Geophys. Res. Lett., 25(10), 1705-1708.

Jaeglé, L., et al. (2000), Photochemistry of $\mathrm{HO}_{x}$ in the upper troposphere at northern midlatitudes, Geophys. Res. Lett., 105(D3), 3877-3892.

Kleinman, L. I., P. H. Daum, Y.-N. Lee, L. J. Nunnermacker, S. R. Springston, J. Weinstein-Lloyd, and J. Rudolph (2005), A comparative study of ozone production in five U.S. metropolitan areas, J. Geophys. Res., 110(D2), D02301, doi:10.1029/2004JD005096

Kormann, R., et al. (2003), Formaldehyde over the eastern Mediterranean during MINOS: Comparison of airborne in-situ measurements with 3Dmodel results, Atmos. Chem. Phys., 3, 851-861.

Lee, Y.-N., et al. (1998), Atmospheric chemistry and distribution of formaldehyde and several multioxygenated carbonyl compounds during the 1995 Nashville/Middle Tennessee ozone study, J. Geophys. Res., 103(D17), 22,449-22,462.

Lelieveld, J., H. Berresheim, S. Borrmann, P. J. Crutzen, F. J. Dentener, H. Fischer, J. Feichter, and P. J. Flatau (2002), Global pollution crossroads over the Mediterranean, Science, 298, 794-799, doi:10.1126/ SCIENCE.1075457.

Millet, D., et al. (2006), Formaldehyde distribution over North America: Implications for satellite retrievals of formaldehyde columns and isoprene emission, J. Geophys. Res., 111, D24S02, doi:10.1029/2005JD006853.

Müller, J.-F., and G. Brasseur (1999), Sources of upper tropospheric $\mathrm{HO}_{x}$ : A 3-dimensional study, J. Geophys. Res., 104(D1), 1705-1715.

Nunnermacker, L. J., J. Weinstein-Lloyd, L. Kleinman, P. H. Daum, Y.-N. Lee, S. R. Springston, P. Klotz, L. Newman, G. Neuroth, and P. Hyde (2004), Ground-based and aircraft measurements of trace gases in Phoenix, Arizona [1998], Atmos. Environ., 38(29), 4941-4956.

Prather, M. J., and D. J. Jacob (1997), A persistent imbalance in $\mathrm{HO}_{x}$ and $\mathrm{NO}_{x}$ photochemistry of the upper troposphere driven by deep tropical convection, Geophys. Res. Lett., 24(24), 3189-3192.

Ravetta, F., et al. (2001), Experimental evidence for the importance of convected methylhydroperoxide as a source of hydrogen oxide $\left(\mathrm{HO}_{x}\right)$ radicals in the tropical upper troposphere, J. Geophys. Res., 106(D23), 32,709-32,716

Ren, X., et al. (2008), $\mathrm{HO}_{x}$ observations and model comparisons during INTEX-A 2004, J. Geophys. Res., 113, D05310, doi:10.1029/ 2007JD009166

Singh, H. B., W. H. Brune, J. H. Crawford, D. J. Jacob, and P. B. Russell (2006), Overview of the summer 2004 Intercontinental Chemical Transport Experiment-North America (INTEX-A), J. Geophys. Res., 111, D24S01, doi:10.1029/2006JD007905.

Snow, J., B. G. Heikes, H. Shen, D. O’Sullivan, A. Fried, and J. Walega (2007), Hydrogen peroxide, methyl hydroperoxide, and formaldehyde over North America and the North Atlantic, J. Geophys. Res., 112, D12S07, doi:10.1029/2006JD007746.

Stickler, A., H. Fischer, J. Williams, M. De Reus, R. Sander, M. G. Lawrence, J. N. Crowley, and J. Lelieveld (2006), Influence of summertime deep convection on formaldehyde in the middle and upper troposphere over Europe, J. Geophys. Res., 111, D14308, doi:10.1029/ 2005JD007001.

Stohl, A., G. Wotawa, P. Seibert, and H. Kromp-kolb (1995), Interpolation errors in wind fields as a function of spatial and temporal resolution and their impact on different types of kinematic trajectories, J. Appl. Meteorol., 34, 2149-2165.

Stohl, A., M. Hittenberger, and G. Wotawa (1998), Validation of the Lagrangian particle dispersion model FLEXPART against large scale tracer experiments, Atmos. Environ., 32, 4245-4264.

Tabazadeh, A., R. J. Yokelson, H. B. Singh, P. V. Hobbs, J. H. Crawford, and L. T. Iraci (2004), Heterogeneous chemistry involving methanol in tropospheric clouds, Geophys. Res. Lett., 31, L06114, doi:10.1029/ 2003GL018775

Wang, Y., and R. G. Prinn (2000), On the roles of deep convective clouds in tropospheric chemistry, J. Geophys. Res., 105(D17), 22,269-22,297.

Wennberg, P. O., et al. (1998), Hydrogen radicals, nitrogen radicals, and the production of $\mathrm{O}_{3}$ in the upper troposphere, Science, 279, 49-53.

Wert, B. P., et al. (2003), Signatures of terminal alkene oxidation in airborne formaldehyde measurements during TexAQS 2000, J. Geophys. Res., 108(D3), 4104, doi:10.1029/2002JD002502.

B. E. Anderson, M. A. Avery, G. Chen, J. H. Crawford, J. R. Olson, L. Thornhill, and S. A. Vay, NASA Langley Research Center, Mail Stop 401B, Hampton, VA 23681, USA

T. H. Bertram and R. C. Cohen, Department of Chemistry and Department of Earth and Planetary Science, University of California, Berkeley, B45 Hildebrand Hall, Berkeley, CA 94705, USA.

D. R. Blake and N. Blake, Chemistry Department, University of California, Irvine, 570 Rolland Hall, Mail code 2025, Irvine, CA 92697, USA.

W. H. Brune and X. Ren, Department of Meteorology, Pennsylvania State University, 504 Walker Building, University Park, PA 16802, USA.

A. D. Clarke and C. S. McNaughton, Depatrment of Oceanography, University of Hawaii, 1000 Pope Road, Honolulu, HI 96822, USA.

G. Diskin and G. Sachse, NASA Langley Research Center, Laser and Electro-Optics Branch, Hampton, VA 23681, USA. 
A. Fried, D. Richter, J. G. Walega, and P. Weibring, National Center for Atmospheric Research, Earth Observing Laboratory, 3450 Mitchell Lane, Boulder, CO 80303, USA. (fried@ucar.edu)

H. Fuelberg, J. Halland, and M. Porter, Department of Meteorology, Florida State University, Tallahassee, FL 32306-4520, USA.

S. R. Hall and R. E. Shetter, Atmospheric Chemistry Division, National Center for Atmospheric Research, 3450 Mitchell Lane, Boulder, CO 80301, USA.

B. G. Heikes and H. Shen, Center for Atmospheric Chemistry Studies, Graduate School of Oceanography, University of Rhode Island, Narragansett, RI 02882-1197, USA.

G. Huey and S. Kim, School of Earth and Atmospheric Sciences, Georgia Institute of Technology, Atlantic, GA 30332-0340, USA.
D. B. Millet, Department of Soil, Water and Climate, University of Minnesota, Borlaug Hall, 1991 Upper Buford Circle, St. Paul, MN 55108, USA.

D. W. O'Sullivan, Department of Chemistry, United States Naval Academy, Annapolis, MD 21402-5000, USA.

K. Pickering, NASA Goddard Space Flight Center, Laboratory for Atmosphere, Greenbelt, MD 20771, USA.

J. Podolske and H. B. Singh, NASA Ames Research Center, Atmospheric Science Branch, Mail Stop 245-5, Moffett Field, CA 94035, USA.

C. Roller, Ekips, Technology Inc., 710 Asp Ave., Suite 500, Norman, OK 73069, USA.

J. A. Snow, Department of Geography, Geology and the Environment, Slippery Rock University, Slippery Rock, PA 16057, USA.

F. Tittel, Electrical and Computer Engineering Department, Rice University, Mail Stop 366, 6100 Main Street, Houston, TX 77005-1892, USA. 